\title{
DEL REPRESENTACIONISMO AL GIRO PRÁCTICO: UNA RECONSTRUCCIÓN DEL CAMPO HISTORIOGRÁFICO DESDE LA DÉCADA DE LOS 90
}

Alejandro Estrella González

\section{INTRODUCCIÓN: DELIMITACIÓN DEL PROBLEMA}

En julio de 1999 tuvo lugar en Santiago de Compostela el II Congreso Internacional de Historia a Debate, en el que más de 200 especialistas tomaron el pulso teórico a la disciplina histórica ${ }^{1}$. Este segundo congreso presentaba una faz completamente nueva respecto al celebrado en 1993, tanto en lo referente a la procedencia de los asistentes como a las temáticas abordadas 2 . Si en 1993 eran las grandes escuelas europeas y norteamericanas las que impusieron su sello al ritmo de los debates, 1999 se constituyó como un verdadero reflejo del proceso de mundialización que estamos viviendo. Paralelamente, si las temáticas que dominaron en el I Congreso giraban fundamentalmente en torno a la crisis de la Historia, en 1999 bien parecía comenzar a otearse nuevas perspectivas que hacían intuir que la somnolencia creativa estaba llegando a su fin. Al adoptar ambos congresos como puntos de referencia bien puede parecer que la disciplina ha encarado por fin una deriva de recomposición tras más de una larga década de crisis. No obstante este juicio quizá deba ser matizado: ni la creatividad y cohesión de la disciplina eran nulas a finales de la década de los ochenta, ni la sensación de optimismo y confianza resultan generalizadas, como antaño, a comienzos del nuevo milenio.

Sea como fuere, en lo que sí parece coincidir la comunidad historiográfica es que durante la última década -período que para algunos llega hasta nuestros días- la historiografía ha vivido una profunda conmoción como consecuencia del agotamiento de las formas de historiar dominantes y la eclosión de dife-

1. Barros, Carlos (ed.), Actas del II Congreso Internacional de Historia a Debate, Santiago de Compostela, 2000, 3 tomos.

2. Barros, Carlos (ed.), Actas del I Congreso Internacional de Historia a Debate, Santiago de Compostela, 1995,3 tomos. 
rentes candidatos a ocupar dicha hegemonía. En términos kuhnianos podemos decir que a lo que hemos asistido a lo largo de la década de los 90 es a un proceso -inacabado- de revolución científica. El uso que hacemos de esta terminología no resulta meramente retórico; si bien, como veremos, adquirirá ciertos matices respecto a la interpretación más extendida entre los historiadores de la propuesta kuhniana ${ }^{3}$. Desde esta perspectiva podemos decir que, por un lado, la crisis de los paradigmas dominantes de la historia social y sociocultural habría respondido al agotamiento de todo el cuerpo teórico y de valores compartidos por la comunidad: desde los principios epistemológicos implícitos (representacionismo ingenuo, representacionismo crítico), a la teoría social desde la que trabajaban (ya en su variante Annales, ya en la del materialismo histórico) pasando por la valoración del papel que la Historia como disciplina debía desempeñar en el universo social (servicio público, revolución social, etc.). Por otro lado, y en tanto que ubicados en un proceso revolucionario, esta crisis paradigmática vendría acompañada de la confrontación entre diferentes candidatos a paradigma dominante, sin que ninguno de ellos haya alcanzado aún una aceptación generalizada.

Este artículo pretende reconstruir esa historia reciente del campo historiográfico, explorar las propuestas en curso y realizar un posible diagnóstico del futuro inmediato. No obstante, nos centraremos en uno de los aspectos del debate, por lo demás de particular relevancia: la discusión epistemológica acaecida en torno a la naturaleza del conocimiento histórico ${ }^{4}$. Desde esta problemática concreta pretendemos dar cuenta de la dinámica del campo historiográfico de la década de los 90 , referida a: la crisis del representacionismo (entendido como el conjunto de principios epistémicos en los que se inspiran la historia social y sociocultural) y las diferentes soluciones ofrecidas por los distintos candidatos en pugna, inspirados en este caso, en las propuestas del giro lingüístico y el giro práctico ${ }^{5}$.

3. V.g. como acabamos de señalar, consideramos la coexistencia de varios paradigmas, si bien uno de ellos siempre ejerciendo como dominante. Recordemos, no obstante, que el mismo Kuhn abre la puerta a la posibilidad de que el paradigma en torno al que se organiza la ciencia en el período de ciencia normal conviva con otros. Respecto a los diferentes usos del vocablo paradigma entre los historiadores: PASAMAR, Gonzalo, "El concepto de paradigma y su importancia en historia de la historiografía", en CABRERA, M. A. y MCMAHON, J. M. (coords.), La situación de la historia. Ensayos de historiografía, Santa Cruz de Tenerife, 2002, pp. 133-155.

4. Privilegiamos esta dimensión del debate porque, a nuestro juicio, es la mejor manera de calibrar la intensidad que ha adquirido el conflicto en el seno de la comunidad durante dicho período: la controversia en torno a la naturaleza del conocimiento histórico nos advierte que lo que ha estado -y está- en juego son, precisamente, las propias reglas del juego.

5. De aquí se deducen ciertas matizaciones controvertidas que, al menos, debemos apuntar. En primer lugar, las propuestas que vamos a denominar como paradigmas responden, exclusivamente, a modelos construidos sobre la base de principios epistémicos compartidos por diversos historiadores a nivel internacional; lo cual, por un lado, no deja de suponer una abstracción -útil-en tanto que lo que realmente existe es una miríada de historiadores que, eso sí, en ocasiones actúan como agentes de forma conjunta; por otro lado, esta definición no se corresponde con la «noción extensa»-más fiel a la propuesta kuhniana- que hemos recogido más arriba (el conjunto de principios, valores y creencias compartidos). Otra cuestión es valorar hasta qué punto las propuestas que se 
En la exposición pueden distinguirse dos partes fundamentales. En primer lugar, presentamos los diferentes paradigmas y su concepción de la naturaleza de la historiografía, organizados según los principios epistémicos en los que se inspiran (representacionismo: apartado 2, giro lingüístico: apartado 3 y giro práctico: apartado 4). De esta manera, y siguiendo un esquema de problemáticas comunes, es posible ir contrastando unos con otros.

Sin embargo, una completa reconstrucción del campo historiográfico y su dinámica no puede quedarse en la descripción de las propuestas teóricas de los diferentes candidatos a paradigma dominante. En concreto se imponen dos exigencias. Por un lado, debemos ser capaces de vincular esos principios normativos a sus condiciones sociales de producción; es decir, vincular los enunciados emitidos a la posición que el enunciador ocupa en el campo social. Simultáneamente, debemos ser capaces de trascender las meras interacciones (sociales y cognitivas) entre los diferentes agentes-enunciadores y establecer así la estructura de relaciones que determina dichas interacciones. Para dotarnos de una herramienta adecuada a tales exigencias nos apoyaremos en la sociología de la ciencia de P. Bourdieu, uno de los programas de ciencias sociales más señeros ubicado en la órbita del giro práctico. No obstante, a nuestro juicio, estas mismas herramientas constituyen por sí mismas -o al menos pueden llegar a constituir- un candidato más a paradigma dominante, por lo que debe ser sometido al mismo análisis y presentación que el resto de candidatos (apartado 5). Esta doble condición (paradigma-herramienta) hace que el capítulo en cuestión actúe de bisagra en relación al siguiente, donde, definitivamente, aplicamos esas herramientas que nos suministra el sociólogo francés para llevar a cabo la reconstrucción del campo historiográfico y su dinámica a lo largo de la década de los 90 (apartado 6).

\section{EL REPRESENTACIONISMO: HISTORIA SOCIAL E HISTORIA SOCIOCULTURAL}

Desde el primer tercio del siglo XX hasta mediados de la década de los 80, la historia social y la historia sociocultural habrían sido consideradas, práctica-

\footnotetext{
inspiran en los mismos principios epistémicos pueden llegar a conformar paradigmas diferenciados, o bien, aun realizando lecturas divergentes de esos recursos epistémicos, sólo constituyen tendencias historiográficas dentro del mismo paradigma. Como tendremos ocasión de ver, quizás en el caso más controvertido (el debate en torno a la valoración de la ruptura de la historia sociocultural respecto a la historia social), hemos optado por considerarlos como paradigmas diferenciados, con el fin de remarcar la particularidad de cada uno de ellos frente al resto. En tercer lugar, y al entender la noción de paradigma en "términos restringidos", es importante tener en cuenta que, cualquier ejercicio que pretenda contrastar los diferentes candidatos entendidos en "sentido extenso" debe contar con la posibilidad de que, aun realizando una lectura divergente de los recursos epistémicos en los que se inspiran, compartan criterios ontológicos o valorativos ( 1. g. el mismo G. Noiriel, ubicado en la órbita del pragmatismo, reconoce que la historia que practica debe mucho a la teoría social desarrollada por $\mathrm{P}$. Bourdieu, sociólogo del que nos valdremos para esbozar el candidato que hemos denominado como crítico-práctico). Norrnel, Gérard, Sobre la crisis de la historia, Madrid, 1997, p. 164.
} 
mente con unanimidad, como las formas adecuadas de hacer historia. Respecto al problema que nos ocupa, podemos decir que ambos paradigmas tendrían en común el compartir una concepción de la naturaleza del conocimiento histórico de corte representacionista.

En líneas generales, esta propuesta se caracteriza por entender que la realidad posee unas cualidades y significados intrínsecos (plano ontológico) que, convertidos en objeto de conocimiento, pueden ser aprehendidos por el sujeto (plano epistemológico) mediante un método adecuado (plano metodológico). A partir de esta concepción, la teoría del conocimiento representacionista queda definida por tres principios básicos. En primer lugar, la relación de conocimiento se entiende bajo lo que podemos denominar como modelo dicotómico. Surgido en el pensamiento moderno a partir de un contexto filosófico dominado por la filosofía de la conciencia, este modelo se caracteriza por entender que en la relación de conocimiento sólo intervienen dos instancias: el sujeto cognoscente y el objeto conocido. En segundo lugar, el conocimiento adecuadamente producido posee la capacidad de representar las cualidades y significados intrínsecos de la realidad objeto de estudio. En tercer lugar, y como consecuencia, el criterio de verdad se deposita en la correspondencia entre el conocimiento producido y esas cualidades de lo real. En definitiva, a partir de estos tres principios se entiende que la naturaleza del conocimiento es de orden representativo.

Ahora bien, la interpretación de esta naturaleza admitiría, no obstante, dos lecturas: bien el conocimiento es una copia o reproducción exacta de los atributos de lo real (lo que podemos denominar como representacionismo ingenuo), bien se trata de un modelo o construcción a partir de dichas cualidades (representacionismo crítico). En el primer caso se entiende que el objeto de conocimiento viene ya dado por la realidad estudiada. De esta forma, la aplicación de una adecuada metodología permite depurar toda interferencia de la esfera subjetiva y en consecuencia una completa adecuación entre el conocimiento y las cualidades de esa realidad objetiva. Por el contrario, para el representacionismo crítico, el objeto de conocimiento es una construcción: éste, no se asimila a una "realidad en bruto", sino a una realidad seleccionada y manipulada por el sujeto desde una determinada teoría y en función de una serie de criterios valorativos. El conocimiento, antes que reproducir las cualidades de lo real es un modelo construido a partir de la mediación entre esos recursos teórico-valorativos del sujeto y aquellos aspectos de la realidad que han sido seleccionados y objetivados. Pero a pesar del sesgo crítico-constructivista, esta lectura no terminaría de abandonar el campo del representacionismo. En primer lugar, porque continúa funcionando desde el espacio definido por el modelo dicotómico, si bien, otorgando un papel activo a la instancia subjetiva. En segundo lugar, porque se sigue considerando que un conocimiento elaborado a partir de una adecuada metodología representa las cualidades de la realidad. La diferencia respecto al representacionismo ingenuo radica en la manera de entender la forma que adquiere esa representación, pero no en el contenido de la misma: mientras que para el primero se trata de una reproducción, para el segundo se trata de un modelo construido a partir de la mediación entre los elementos subjetivos 
y las cualidades de la realidad objetivada. Finalmente y en tercer lugar, porque se sigue entendiendo que la normatividad que regula la adecuada producción de un modelo viene sancionada en última instancia por esas cualidades: lo que otorga validez a unos modelos sobre otros es su grado de correspondencia, su capacidad para representarlas.

En definitiva, como habíamos señalado, este representacionismo epistemológico constituye el horizonte desde el que, tanto la historia social como la historia sociocultural, concebirían la naturaleza del conocimiento histórico: a partir del espacio binario que delimita el modelo dicotómico, ambos paradigmas entienden el conocimiento histórico como una suerte de representación de los significados intrínsecos de la realidad histórica. Por otro lado, la distinción entre representacionistas ingenuos y críticos toma cuerpo en el seno de la historia social, donde llegan a convivir representantes de ambas propuestas. Por contra, aquellos historiadores que desde finales de los años 70 integran el paradigma de la historia sociocultural abrazan definitivamente -en consonancia con la teoría social desde la que trabajan- el representacionismo crítico. Ahora bien, desde esa misma década somos testigos de cómo en diferentes ámbitos intelectuales y científicos eclosionan propuestas que comienzan a cuestionar los principios de la epistemología representacionista. La disciplina histórica no quedaría al margen de este fenómeno. Su irrupción en el campo historiográfico a partir de la década de los 80 contribuiría decisivamente al agotamiento de los paradigmas de la historia social y sociocultural.

\section{EL GIRO LINGÜISTICO: NUEVA HISTORIA SOCIAL Y TEXTUALISMO}

Uno de los hitos que abanderaría esta empresa crítica ha sido denominado desde diferentes ámbitos como giro lingüistico (GL). Fenómeno que acontece al abrigo de una filosofía del lenguaje que, desde mediados del siglo XX, se iba constituyendo como alternativa a la filosofía de la conciencia, su irrupción en el campo de las ciencias sociales habría supuesto una verdadera reorientación teórica de perfiles específicos, según la disciplina o la tradición teórica y nacional en la que hallara eco ${ }^{6}$.

En líneas generales, cabe caracterizar al GL como un conjunto de propuestas que tienen en común el ofrecer una nueva teoría de la producción de significados a través de una nueva concepción del lenguaje ${ }^{7}$. En este sentido, cabe destacar dos principios básicos. En primer lugar, se entiende que el lenguaje posee una naturaleza autónoma: estableciendo una decisiva distinción entre los significados de lo real y la matriz de categorías que permite esta operación, reconoce en esta última -generalmente denominada como discurso- una esfera social específica

6. En líneas generales se trata de un amplio espectro surgido a raíz del "problema del lenguaje» (Foucault, Michel, Estética, ética y hermenéutica, Barcelona, 1999, p. 311) que abarca desde postestructuralistas, a herederos del segundo Wittgenstein, pasando por seguidores de la semiótica de Barthes, de la deconstrucción de Derrida o de la antropología cultural de Geertz.

7. Cabrera, Miguel Á., Historia, Lenguaje y Teoria de la Sociedad, Madrid, 2001, p. 43. 
dotada de una lógica histórica propia. En segundo lugar, se entiende que el lenguaje posee una dimensión constitutiva, lo que modifica la secular forma de entender la relación referente-significado. La nueva teoría consideraría que la realidad (referente material) carece de significados intrínsecos, por lo que el lenguaje no puede continuar concibiéndose como un vehículo de expresión que transmite o expresa dichos significados. Al contrario, en tanto que no se trata de atributos inherentes, los significados del referente son adquiridos por la acción de la matriz discursiva que opera en cada caso. En conclusión, los significados que designan las cualidades de lo real dejan de considerarse como representaciones de ésta y pasan a entenderse como efectos de las formas y contenidos de la matriz discursiva.

Como podemos atisbar, esta nueva teoría del lenguaje y de la producción de significado supone un profundo cuestionamiento de los tres principios que articulaban la epistemología representacionista. En primer lugar, al considerar el discurso como un cuerpo de categorías y reglas de significación autónomo mediante el que los individuos dotan de significado a la realidad (creando objetos) y a sí mismos (sujetos), el modelo dicotómico queda inhabilitado, al entenderse que no son dos, sino tres las instancias que intervienen en la práctica del conocimiento. En segundo lugar, dado que los significados no son atributos intrínsecos de lo real, deja de existir un vínculo directo a-lingüístico entre el referente y el significado, entre la realidad y el conocimiento. Por tanto, el conocimiento no puede continuar concibiéndose como un acto representación de unas supuestas cualidades de lo real; y, en la misma línea, no es posible fundamentar la normatividad que debe regular la relación de conocimiento sujeto-objeto sobre dichas cualidades. Finalmente, y en consecuencia, el criterio de verdad como correspondencia debe ser desechado.

Desde la década de los años 80 , esta crítica a la epistemología representacionista de la mano de los recursos del GL irrumpe en el campo historiográfico, materializándose en diferentes propuestas que cuestionan la hegemonía de la historia social y sociocultural e imponen el ritmo del debate historiográfico durante buena parte de los años 90 . Para estas propuestas el conocimiento histórico ya no representa (sea como copia, sea como modelo) la realidad histórica, sino que es el resultado de una operación retórica de construcción significativa de la misma: la naturaleza de la investigación histórica deja de ser representativa y deviene narrativa ${ }^{8}$. Ahora bien, la manera de entender esta "nueva" naturaleza de la historiografía admite diferentes interpretaciones. Vamos a destacar dos.

Uno de los candidatos a paradigma dominante inspirado en el GL ha sido denominado como "nueva historia" (new history) o "nueva historia social" (new social history) $)^{9}$. Para la "nueva historia», el historiador trabaja ya desde un

8. VAzQUEZ, Francisco, "El problema de la explicación en historia de las mentalidades», en Barros, C. (ed.), Actas del I Congreso Internacional de Historia a Debate. Tomo II. El Retorno del Sujeto, Santiago de Compostela, 1995 , p. 38.

9. Entre los integrantes de este candidato a paradigma destacan, entre otras, las figuras de P. Joyce, J. Z. Lockman, W. Scott, W. H. Sewell o J. Vernon (CABrerA, Miguel Á., Historia, Lenguaje..., pp. 17-18.). 
determinado patrón lingüístico autónomo (teorías y conceptos con reglas propias de significación) que media con la realidad histórica, determinando la forma de organizar los hechos (acontecimientos, estructuras y procesos históricos) y de producir su inteligibilidad ${ }^{10}$. En otras palabras, los "actos de significación» implícitos en la investigación histórica no vienen determinados por la naturaleza de los hechos mismos, sino por la mediación de éstos con la matriz discursiva. Por tanto, el criterio de verdad como correspondencia debe sustituirse por un criterio que atienda a la operación retórica mediante la que se han organizado significativamente los hechos históricos y se ha elaborado una trama con ellos. En concreto, al contrastar la validez de diferentes relatos habrá de valorarse la plausibilidad del uso de las estructuras lingüísticas; por un lado, a la hora de crear el objeto de estudio (es decir, la mediación del lenguaje en tanto que categorias prefigurantes); por otro lado, a la hora de elaborar una trama con dicho objeto (el uso de las convenciones retóricas que permiten dicha operación) ${ }^{11}$.

Ahora bien, una lectura altemativa del arsenal teórico que ofrece la nueva teoría del lenguaje viene de la mano del denominado narrativismo escéptico o textwalismo. En líneas generales, el textualismo se caracteriza por defender la inexistencia de un corte epistemológico entre relato histórico y relato de ficción ${ }^{12}$. Sin lugar a dudas esta propuesta ha creado una gran polémica y un fuerte rechazo, incluso entre no pocos "nuevos historiadores». La piedra de toque de la controversia cabe situarla en la constatación textualista, a raíz del arsenal suministrado por la semiótica de R. Barthes y la deconstrucción de J. Derrida, de la incapacidad del lenguaje para trascender nada más allá de sus propios límites. Para los textualistas, una vez que se admite la naturaleza autónoma y constitutiva del lenguaje quedan rotos todos los vínculos con la realidad, de manera que su concurso queda definitivamente aplazado y es sustituido por un lenguaje autorreferencial que nos introduce en un círculo ad infinitum de interpretación y escritura: la realidad, ya mediada significativamente, aunque parece y dice estar presente en el texto, nunca es accesible para el historiador, desaparece como tal y sólo queda el texto ${ }^{13}$. Es en este sentido en el que se afirma que el pasado no está presente en el texto sino como efecto del discurso, y de aquí que, el discurso histórico, en tanto que construcción lingüística sin correspondencia alguna con la realidad, no difiera esencialmente del discurso de ficción. El hecho de que aquél alegue hacer referencia

10. JOYCE, Patrick, "History and postmodenism", Past and Present, 133 (1991), p.133.

11. Cabrera, Miguel Á., "La situación actual de la historia: un paisaje cambiante", en Cabrera, $M$. Á. y MCMAHON, J. M. (coord.), La situación de la Historia. Ensayos de historiografía, Santa Cruz de Tenerife, 2002, pp. 32-33.

12. VÁzQUEZ, Francisco, "El problema de la explicación en historia...», p. 38. En este candidato a paradigma cabe situar la retórica de la historia de H. White y F. Ankersmit, la semiología de A. J. Greimas, la historia de la literatura de L. Paterson, la "new intellectual history" de La Capra o la historia ficción de S. Schama (VÁzouez, Francisco, "La Controversia entre Historia...", pp. 99-100).

13. BARTHES, Roland, "El discurso de la historia», en El susurro del lenguaje, Barcelona, 1987, p. 174 y Derrida, Jaques, De la gramatología, Buenos Aires, 1971, p. 16. 
a hechos que «realmente ocurrieron» no tendría ninguna relevancia, pues el discurso de ficción también puede hacerlo ${ }^{14}$. De hecho, los textualistas reconocen que la apelación de la epistemología representacionista a la objetividad (la historia posee un sentido inherente), a la ciencia (éste puede ser desvelado mediante un adecuado método de investigación) y a la verdad (el resultado de la investigación es una representación total o parcial del sentido de la historia) no sería más que un recurso retórico para potenciar la eficacia de su discurso, su fuerza sugestiva ${ }^{15}$. En consecuencia, dado que las narraciones históricas no difieren en esencia de los relatos literarios, el único criterio del que disponemos a la hora de contrastarlos responde a un tratamiento de crítica textual que atienda - exclusivamente- al análisis formal de las estructuras lingüísticas (categorías prefigurantes y convenciones retóricas) ${ }^{16}$.

En cierto sentido, el textualismo no haría más que llevar a sus últimas consecuencias la vía abierta por la nueva concepción del lenguaje del GL. Sin embargo, como hemos señalado, no pocos «nuevos historiadores» han tomado distancia respecto a la pretensión textualista de disolver las barreras entre relato histórico y de ficción. Para éstos, el relato histórico adquiere un perfil específico dentro del marco de los relatos, en tanto que la mediación discursiva requiere el concurso de la realidad histórica, si bien ésta, a diferencia del representacionismo, no determina significativamente dicha mediación; papel que queda reservado a la matriz discursiva empleada por el historiador. En definitiva, mientras que los representacionistas olvidan que entre la producción historiográfica y la realidad histórica no existe un vínculo directo a-lingüístico, los textualistas pasan por alto dicho vínculo y reducen la lógica del relato histórico a la de ficción.

Sea como fuere, podemos concluir que la irrupción del GL en el campo historiográfico habría trastocado radicalmente la forma de encarar el problema de la naturaleza del conocimiento histórico, al sustituir la pregunta por los mecanismos que posibilitan la adecuación entre la producción del historiador y la realidad histórica (es decir, por la relación entre sujeto y objeto de conocimiento) por el análisis de la matriz discursiva que actúa en cada caso y los procesos lingüísticos que desembocan en la producción de relatos históricos. En pocas palabras, desde los años 80 somos testigos cómo de forma progresiva el clásico enfoque epistemológico representacionista ("¿cuál es la estructura del conocimiento histórico?») es sustituido por un enfoque semiótico («qqué trazas específicas caracterizan a las narraciones históricas en el marco general de los relatos?») ${ }^{17}$. Pese a las diferentes lecturas, es posible concluir que para los candidatos a paradigma dominante inspirados en el GL, la naturaleza del conocimiento histórico, antes que representativa, es de orden narrativo.

14. CABReRA, Miguel Á., "La situación actual de la historia...", p. 33.

15. BARTHES, Roland, "El discurso...", pp. 175-176.

16. WHITE, Hyden, Metahistory. The historical imagination in nineteenth-century Europe, London, 1973, p. 10.

17. Vázquez, Francisco, "El problema de la explicación en historia...», p. 38. 


\section{EL GIRO PRÁCTICO: NARRATIVISMO CRITICO Y PRAGMATISMO}

El otro hito que junto al GL ha venido a cuestionar radicalmente el realismo epistemológico es el denominado giro práctico (GP). Inspirado en una filosofía pragmática que, desde la segunda mitad del siglo XX iría hallando eco en diferentes tradiciones, el GP se va configurando simultáneamente en la escena de las ciencias sociales ${ }^{18}$. Este heterogéneo conjunto de propuestas se caracterizaría por compartir, al menos, una nueva teoría de la práctica. En líneas generales, esta teoría supone una nueva concepción de los procesos sociales y cognitivos, al entender que éstos no son proyecciones de las esferas subjetivas u objetivas, ni el resultado de la actualización de códigos semióticos, sino efectos de situaciones de orden práctico. La naturaleza de dichos procesos responde a situaciones activas en las que se dan una serie de interacciones entre los individuos y entre éstos y su medio; interacciones en las que aquéllos -dotados de unos determinados recursos- no eligen entre acción e inacción (o contemplación) sino entre diferentes cursos de acción, a partir de los cuales construyen espacios de objetividad y subjetividad ${ }^{19}$.

De esta manera, la reflexión epistemológica adquiere un nuevo cariz. El GP va a sustituir el enfoque representacionista (análisis de los mecanismos que regulan la relación sujeto-objeto) y el semiótico (análisis de la matriz discursiva que actúa generando la relación sujeto-objeto) por uno praxeológico: el análisis de las prácticas intersubjetivas a la hora de definir la relación (práctica) del sujeto con el objeto ${ }^{20}$. En consecuencia, somos testigos de cómo el GP no sólo cuestiona los principios de la epistemología representacionista, sino que ofrece una alternativa a la propuesta del GL.

Respecto al representacionismo, la nueva teoría de la práctica supone, en primer lugar, el abandono definitivo del modelo dicotómico, toda vez que introduce una nueva esfera (la práctica) a partir de la cual se constituye la relación sujeto-objeto. De aquí que se considere que la normatividad que regula dicha relación no viene sancionada en última instancia por las cualidades de lo real, sino por el resultado efectivo de esas situaciones prácticas: el conocimiento deja de entenderse como una representación de lo real y deviene una construcción, pero cuyas reglas -a diferencia del representacionismo crítico- se definen en el curso de prácticas intersubjetivas. En tercer lugar, y como consecuencia, el criterio de verdad-correspondencia debe ser sustituido.

18. Destacando entre sus precursores a Marx, los pragmatistas norteamericanos o el segundo Wittgenstein, el GP responde a un amplio marco -en ocasiones contradictorio- en el que se ha llegado a incluir desde el neopragmatismo, a la teoría de la acción comunicativa de Habermas, pasando por el estructuralismo constructivista de Bourdieu o la microfísica de Foucault, entre otros (ReHG, W. J. et al., Pluralism and the Pragmatic Turn. The Transfornation of Critical Theory, Cambridge Ma., 2001, p. 18 y SCHATzKI, T. R. et al., The practice turn in Contemporany Theory, London, 2001, p. 1.

19. Sevilla, "Práctica», en Muñoz, J. y Velarde, J. J. (eds.), Compendio de Epistemología, Madrid, 2000, p. 467 y Vázouez, Francisco, "Foucault y la Historia Social», Historia Social, n. 29 (1997), p. 153.

20. Bourdieu, Pierre, El oficio del científico. Ciencia de la ciencia y reflexividad, Barcelona, 2003, p. 129. 
Respecto al GL, la relación resulta más ambigua, fundamentalmente porque el GP no deja de asumir ciertos aspectos de la nueva teoría del lenguaje, en concreto aquel que hace referencia al carácter constitutivo del discurso. Ahora bien, no ocurre igual respecto a la naturaleza autónoma que le otorga el GL. El GP rompe con dicha concepción al abordar el problema del lenguaje desde la cuestión de su uso, de las condiciones sociales de su utilización. En este sentido, se entiende que el lenguaje no forma un universo aparte de las relaciones sociales que conforman las diferentes situaciones prácticas ${ }^{21}$. Imbricado en dichas relaciones, deja de concebirse como una estructura o matriz conceptual, para entenderse como uno de los tipos de curso de acción que se les presenta a los individuos en sus interacciones con otros individuos y con el medio; en otras palabras, el lenguaje se constituye como una actividad de orden práctico ${ }^{22}$. De aquí que, a diferencia del GL, el GP insista en que la normatividad que regula la producción de conocimientos no es, exclusivamente, efecto retórico de las formas y contenidos de la matriz discursiva, sino el resultado de situaciones prácticas de orden discursivo y no discursivo. Finalmente, los criterios de valoración basados en el análisis de dichas operaciones retóricas, deben ser ampliados ${ }^{23}$.

El GP hará su aparición en el campo historiográfico a mediados de los años 90 sirviendo de fuente de inspiración a una serie de historiadores que, considerando teóricamente agotado el representacionismo de la historia social y sociocultural, pretenden presentar una alternativa a las propuestas inspiradas en el GL. En esta dirección se mueve el narrativismo crítico ${ }^{24}$. En líneas generales, el narrativismo crítico se caracteriza por asumir la condición narrativa de la historiografía e insistir, simultáneamente, en que el relato histórico debe satisfacer unas determinadas exigencias epistemológicas. Mientras que con la primera característica se aleja del representacionismo de la historia social y sociocultural, con

21. Bourdiev, Pierre, ¿Qué significa hablar? La Economia de los Intercambios Lingüísticos, Madrid, 1985, pp. 67 y 77 .

22. SCHATZKI, T. R., The practice turn..., p.3. De hecho, se reconoce la distinción ya operada por Foucault, entre dos tipos de prácticas sociales: prácticas no discursivas y prácticas discursivas; de forma que la lógica de las primeras no se reduce a la de las segundas (CHarTier, Roger, "Foucault et les historiens, les historiens et Foucault. Archéologie des discours et généalogie des practiques: à propos de la Révolution", en. Franche, D. J. et al. (comps.), Au risque de Foucault, Paris, 1997, pp. 228-229.).

23. Insistimos en la heterogeneidad de las propuestas que se mueven en el ámbito del GP. Así, por ejemplo, Bourdieu critica a Habermas por entender el lenguaje como un ente autónomo, si bien, la propuesta del pensador alemán adquiere unos perfiles específicos que impiden encuadrarla en las filas del GL (Bourdieu, Pierre, ¿Qué significa hablar?..., p. 67).

24. En este grupo destacan autores como R. Chartier, P. Ricoeur, B. Lepetiti, J. Revel, J. Topolsky o la obra reciente de C. Ginzburg, entre otros (VÁzauzZ, Francisco, «La Controversia entre Historia...", 101). Cabe señalar, no obstante, que esta propuesta recibe denominaciones distintas según el ámbito en el que nos ubiquemos. Así, en Francia, en el entorno de la escuela de Annales se hablará de "giro crítico" ("Histoire et sciences sociales. Un tournant critique?», Annales E.S.C, 2, marzo-abril, 1988); mientras que, por ejemplo, C. Ginzburg nos habla del "paradigma indiciario" para designar una concepción de la historiografía en términos similares a lo que aquí denominamos como narrativismo crítico (GuinzBurG, Carlo, "Spie. Radici di un paradigma indiziario", en Miti, emblemi, spie, 1992). 
la segunda se pretenden conjurar los peligros de un textualismo que asemeja las narraciones históricas a las de ficción ${ }^{25}$. Efectivamente, para el narrativismo crítico el historiador produce, a partir de unos determinados recursos lingüísticos, objetos históricos y tramas narrativas que no guardan una relación de correspondencia con la realidad histórica. Ahora bien, inspirándose en las propuestas del GP, considera la necesidad de abordar la relación sujeto-objeto en términos prácticos (no exclusivamente lingüísticos), así como de dar cuenta de las prácticas intersubjetivas que definen las reglas que gobiernan dicha relación.

En el primer caso, como hemos señalado, entender la relación sujeto-objeto en términos prácticos implica asumir que en la construcción del relato histórico están involucrados, no sólo elementos de orden discursivo, sino también otros de orden no discursivo. Estos últimos revelarían la presencia de una exterioridad al propio lenguaje que ejerce una presión sobre el uso que el historiador hace de la matriz discursiva. Para el narrativismo crítico, concebir e insistir en la presión de estos elementos extra-lingüísticos es precisamente lo que permite elevar una sólida barrera frente a las pretensiones textualistas, en tanto que instaura una serie de frenos o regulaciones no retóricas al uso de la matriz discursiva. Estos elementos establecerían esos frenos a tres niveles. En primer lugar en el material mismo con el que trabaja el historiador: el documento histórico. A diferencia de la literatura, el pasado, cuando se aborda desde el campo de la historiografía, no admite una libre manipulación retórica, toda vez que el documento histórico posee un carácter recibido y no inventado ${ }^{26}$. El historiador, por tanto, no puede producir el "material" con el que trabaja ad libitum, antes bien, debe someter su «creatividad» a los límites que le impone dicho carácter heredado. En segundo lugar, a la hora de llevar a cabo la lectura del documento. Retomando la distinción entre prácticas discursivas y no discursivas, el narrativismo crítico sostiene que la realidad investigada por el historiador no se agota en el análisis del discurso. A partir de esta constatación, el narrativismo crítico reconoce que un mismo documento histórico puede ser leído de modo constatativo (como si informara de prácticas no discursivas: fluctuaciones demográficas, gestión del espacio, prácticas de disciplinización, etc.) o de modo performativo (analizándolo como práctica discursiva) ${ }^{27}$. De esta forma, al asumir la necesidad y la posibilidad de abordar el análisis de prácticas no discursivas, el narrativismo crítico no sólo consigue escapar del círculo vicioso al que aboca la concepción autorreferencial del lenguaje con la que trabaja el textualismo, sino que impone un freno al uso exclusivo de las técnicas de crítica textual. En tercer lugar, y en esta misma línea, el narrativismo crítico reconocería el carácter práctico y no exclusivamente discursivo de las técnicas propias de la historiografía,

25. No obstante, como veremos, al adoptar los recursos teóricos del GP con el objetivo explícito de conjurar dicha amenaza, la propuesta del narrativismo crítico acaba constituyéndose como una alternativa a la new social history.

26. Chartier, Roger, "Narración y verdad", El País-Temas de Nuestro Época, 289 (1993), p. 4.

27. Spregel, Gabrielle, "History ad post-modernims IV", Past and Present, 135 (1993), p. 201 y VÁzQUEZ, F., «Foucault y la Historia...», p. 158. 
diferenciando entre el uso de prácticas discursivas ( $v$. g. el utillaje conceptual) y el de no discursivas ( $v . g$. uso de determinadas técnicas arqueológicas, ejercicio de trascripción de documentos o elaboración de fichas). En definitiva, la presión de estos tres elementos extra-lingüísticos suponen una serie de frenos e instauran un régimen de reglas o procedimientos cognitivos a los que, a diferencia del literato, el historiador debe ajustar el uso creativo de los recursos discursivos a la hora de construir objetos y elaborar relatos históricos: para el narrativismo crítico la normatividad que regula la relación sujeto-objeto, antes que de retóri$\mathrm{CO}$, es de orden epistemológico ${ }^{28}$.

Ahora bien, a diferencia del representacionismo, esta normatividad de orden epistémico no viene sancionada por unas supuestas cualidades intrínsecas a la realidad histórica; antes bien, dicha normatividad no es sino el resultado de una práctica intersubjetiva. Si nos fijamos en los niveles en los que el narrativismo crítico ubica las presiones extralingüísticas a las que está sometida la construcción de relatos históricos, vemos como ninguno apela a cualidades de la realidad histórica, sino que conciernen al propio oficio del historiador. En otras palabras, esa práctica colectiva que define la relación sujeto-objeto no es más que el desempeño colectivo del oficio historiográfico. De esta manera, la normatividad que regula la relación sujeto-objeto responde a las reglas cognoscitivas implícitas en dicho oficio. Y dado que estas reglas no vienen sancionadas por una realidad exterior a la propia práctica, no pueden ser sino convenciones heredadas y aprendidas por el historiador; de ahí, precisamente, que el régimen de verdad que éstas instauran adquieran validez intersubjetiva.

En conclusión, el narrativismo crítico levanta una barrera epistemológica entre el relato histórico y de ficción al insistir en la existencia de un régimen de verdad (a diferencia del textualismo) que, sin embargo, ni viene sancionado por las cualidades de lo real (a diferencia del representacionismo de la historia social y sociocultural), ni puede entenderse, exclusivamente, como efecto retórico de la mediación discursiva (a diferencia de la "nueva historia»). Antes bien, este régimen de verdad -en el que se encuentran implicadas prácticas discursivas y no discursivas- vendría sancionado en última instancia por las convenciones implícitas en el oficio del historiador: la naturaleza de la historiografía deja de entenderse como representativa o narrativa y deviene práctica sujeta a convención.

Una segunda lectura de los recursos teóricos que suministra el GP ha sido denominada como pragmatismo. Quizás una de las interpretaciones más sistemática de esta propuesta historiográfica es la que realiza G. Noiriel en su libro Sobre la crisis de la Historia ${ }^{29}$. Como buen pragmatista Noiriel parte de un

28. LEPETT, Bernard, "Le présent de l'histoire», en LEPETT, Bernard (dir.), Les formes de l'expérience. Un autre histoire sociale, Paris, p. 273.

29. El pragmatismo en historiografía admite, sin embargo, diversas lecturas. Optamos no obstante por la vía que propone Noiriel, no sólo por su claridad expositiva, sino porque a diferencia del pragmatismo de autoras como J. Appleby, L. Hunt o M. Jacob-quienes, influenciadas por la obra de $\mathrm{H}$. Putman pretenden cierto equilibrio entre pragmatismo y realismo- asume, influenciado en este caso por el neopragamatismo norteamericano de J. Dewey y R. Rorty, un claro 
problema concreto: ante la fragmentación a la que se enfrenta la historiografía -alimentada por toda una suerte de nihilismos posmodernos- ¡es posible reconstruir la disciplina y recuperar la cohesión perdida? Pero antes debemos responder a otra pregunta ¿sobre qué clase de principios cabe sustentar esta reconstrucción?

De entrada, el pragmatismo entiende que la disciplina no recuperará la cohesión si los historiadores continúan introduciendo en sus disputas problemáticas referentes a la naturaleza del conocimiento o al estatus de la realidad; problemas de índole filosófica que les obligan a hablar en un lenguaje que no les es propio $^{30}$. Pero esta llamada a la necesidad de centrar el debate en los problemas concretos que afectan a los historiadores no es suficiente. En su intento por contrarrestar los efectos disgregadores de los textualistas, el narrativismo crítico habría contado con el acierto de apelar al propio oficio del historiador antes que a una realidad exterior. No obstante, habría cometido el error de entender este oficio, exclusivamente, en términos de operaciones cognitivas. De aquí se derivan dos problemáticas desde las que podemos ir perfilando la propuesta pragmatista $^{31}$. En primer lugar, al entender la intersubjetividad que regula la relación. sujeto-objeto en términos de convenciones cognitivas, el narrativismo crítico dejaría en suspenso las formas de vida asociadas a la comunidad historiográfica, la dinámica social interna y externa que la caracteriza: ¿en qué universo institucional y sociológico se despliega el ejercicio de ese oficio?, ¿cómo se comunica?, ¿qué efectos produce en el auditorio? En segundo lugar, y en esta misma línea, se considera que la solución teórico-cognitiva del narrativismo crítico es demasiado frágil para afrontar la fragmentación y la amenaza de ciertos nihilismos posmodernos. Efectivamente ¿por qué esas convenciones epistémicas a las que según el narrativismo crítico se somete el historiador deben ser preferibles a otras?, o dicho de otro modo ¿̇ónde reside la fuerza vinculante de esas convenciones? Para el pragmatismo dar respuesta a estas cuestiones y comenzar una labor de reconstrucción colectiva de la disciplina pasa, no sólo por abandonar la búsqueda de un fundamento exterior al propio ámbito del oficio, sino por desplazar la discusión del plano de la razón teórica al de la razón práctica: los principios en los que apoyar la reconstrucción de la disciplina serán, en última instancia, antes que de orden cognoscitivo, de orden ético.

Por tanto, el pragmatismo cree necesario, en primer lugar, sostener la existencia de una disciplina (cohesionada, reconocida, etc.) sobre las prácticas que

distanciamiento frente a toda propuesta representacionalista. Sobre el pragmatismo historiográfico de Appleby, Hunt y Jacob, véase APPELBY, Joyce et al., Telling the truth about history, New York, 1994.

30. Desde luego no se trata de negar la filosofía y la reflexión teórica. Como veremos lo que se cuestiona es la búsqueda por parte de los historiadores de fundamentos filosóficos con los que apuntalar sus posiciones en las disputas de competencia. Noiriel entiende que los historiadores deben acudir a la filosofía (y a las ciencias sociales) para solucionar problemas concretos y llevando a cabo un ejercicio de "traducción» al lenguaje historiográfico (NoIRIEL, Gérard, Sobre la crisis..., pp. $43-44$ y $178-179$ ).

31. Ibidem, pp. 153-159. 
definen las formas de vida de una determinada comunidad cientifica. De esta forma, Noiriel va a definir la disciplina historiográfica como el conjunto de actividades en las que están implicados todos los individuos que ejercen el "oficio de historiador ${ }^{32}$. Estas actividades son de tres tipos: la producción de saber (según los criterios y normas definidos por la comunidad historiográfica), la difusión de estos conocimientos (contribuyendo de esta manera a la constitución de la memoria colectiva) y las relaciones de poder implícitas en las actividades de juicio y nombramiento. Noiriel parte de la tensión entre estas tres actividades para esbozar el estado de crisis actual de la disciplina y proponer una reconstrucción de la misma en términos pragmatistas; es decir, en términos de prácticas comunicativas y de consenso guiadas, como hemos señalado, por principios éticos ${ }^{33}$.

Una comunidad (científica) se define por el uso de un lenguaje compartido (fruto o expresión de un oficio constituido como patrimonio común) que permite a sus miembros explicitar criterios de acción, definir problemas, contrastar conocimientos. En definitiva, permite consensuar la normatividad que regula la producción de verdad (definida como opinión sobre lo que hay acuerdo) y transmitir estos conocimientos a otras comunidades. De aqui se deriva una tensión entre las dimensiones del saber y la memoria: mientras que la sociedad a través del Estado delega en la comunidad la tarea de definir los criterios de juicio, la somete -a través de determinados grupos (entre ellos el mismo Estado)- a una presión con el fin de orientar esa producción de saber y su difusión como memoria. Esta tensión se ha decantado en los últimos tiempos en detrimento de la autonomía de la disciplina y por ende de su lenguaje compartido. Desde una perspectiva pragmatista la cuestión que deben acordar los historiadores es si desean recuperar cotas de autonomía y un lenguaje compartido. Si es así, la comunidad debe responder ante esa presión cohesionándose, para lo que es necesario recuperar el espíritu de comunidad implícito en la tradición del oficio heredado (en concreto se apela a la figura de M. Bloch) y desarrollar prácticas de solidaridad colectivas entre sus miembros (entendidas como todas aquellas acciones que tienden al mayor acuerdo intersubjetivo posible).

Esta última reflexión nos introduce en el segundo binomio. Si bien esta solidaridad es un factor de cohesión, la competencia entre los historiadores actúa como elemento de disgregación. Esta competencia en la que se basan todas las relaciones de poder de la comunidad encuentra su expresión más evidente en las actividades de juicio sobre la producción de conocimientos (y concretamente en los nombramientos oficiales). Pero, por otro lado, los protocolos que regulan estas actividades de juicio constituyen un elemento definitorio del oficio y del lenguaje compartido por la comunidad historiográfica, delimitando un ámbito de competencia atribuido a los integrantes de la misma. De este doble carácter de las actividades de juicio cabe deducir que identificar un oficio científico no pasa, exclusivamente, por determinar un "saber hacer» (al

32. Ibidem, p. 179.

33. Ibidem, pp. 178-201. 
estilo de los narrativistas críticos) sino comprender cómo se articula la tensión entre la producción del saber y las relaciones de poder que le son propias. El desafío al que se enfrenta toda disciplina que se pretenda científica (autónoma) responde, por tanto, a la necesidad de delimitar un conjunto de actividades y de competencias, de modo que los conocimiento producidos en el interior de ese segmento del saber puedan evaluarse a partir de criterios compartidos por todos los que se incorporan a él. En este sentido, el cuestionamiento actual de la condición científica de la disciplina histórica responde a la incapacidad de los historiadores -como consecuencia de la proliferación de discursos- para llegar a acuerdos sobre los protocolos que deben regular las actividades de juicio y delimitar así, un conjunto de actividades de competencias propias. La solución que propone Noirel -antes que apostar por un fundamento epistémico contra esta suerte de relativismo- pasa por fomentar una práctica democrática, entendida como un ejercicio de transparencia, por el que los historiadores clarifican el lenguaje utilizado y explicitan sus "punto de vistas». A partir de aquí sería posible consensuar los protocolos que deben regular las actividades de juicio, de forma que, conocidos y compartidos, éstas adquieran un carácter más justo y, en consecuencia, nuestros conocimientos resulten más verdaderos (en tanto que sólo pueden considerarse como tal si así ha sido convenido por la comunidad).

En definitiva, el pragmatismo pretende una reconstrucción de la disciplina delimitando problemas concretos a los que debe hacer frente la comunidad historiográfica; problemas que encuentran solución en el ejercicio de unas prácticas comunicativas que apuntan a la consecución de acuerdos intersubjetivos sobre la base de un oficio heredado y compartido. Estas prácticas no se apoyan ya sobre fundamentos onto-epistémicos sino que, insertas en las formas de vida de la comunidad, deben guiarse por los principios éticos de solidaridad y justicia. La naturaleza del conocimiento histórico deja de considerarse de orden representativo, retórico o cognitivo-convencional y deviene práctica democrática del consenso.

\section{LA PROPUESTA CRITICO-PRÁCTICA}

Como señalábamos en la introducción, el objetivo de este apartado es dotarnos de recursos teóricos que nos permitan reconstruir el campo historiográfico y su dinámica durante la última década. En pos de dicho objetivo, cabe apelar a lo que podemos considerar una nueva propuesta que, inspirada en el GP, ofrece una alternativa al problema de la naturaleza de la historiografía. Este apartado admite por tanto dos lecturas: recurso teórico para nuestro trabajo y nuevo candidato a paradigma dominante. Como habíamos señalado, esta propuesta que hemos acertado a denominar como crítico-práctica proviene de la aplicación al campo historiográfico de la sociología de la ciencia de P. Bourdieu ${ }^{34}$.

34. No obstante, como defenderemos en el próximo apartado, es posible vincular esta propuesta que aquí teorizamos a cierta historiografía foucaultiana y a ciertos herederos del materialismo histórico. 
En líneas generales dicha propuesta se caracterizaría por asumir en gran medida la crítica que el pragmatismo realiza al narrativismo crítico. Efectivamente, la situación práctica intersubjetiva a partir de la cual se define la relación sujetoobjeto, no sólo goza de una dimensión cognitiva (y por tanto las presiones a las que está sometida la elaboración de relatos históricos no sólo son de orden epistémico), sino que, inmersa en las relaciones que regulan la vida académica de la comunidad historiográfica, poseen una dimensión social. Ahora bien, la solución que ofrece el pragmatismo tampoco resultaría satisfactoria. Excesivamente condicionado por la percepción de una comunidad en peligro de desintegración aspira a ofrecer un programa de acción mediante el que superar los conflictos: la necesidad (ética) de explicitar un lenguaje común mediante el que alcanzar acuerdos concretos desde el horizonte del oficio heredado. Pero, una vez que se ponen en marcha procesos de discusión con el fin de dirimir los conflictos ¿cómo estamos seguros de que los acuerdos intersubjetivos alcanzados son realmente libres y no enmascaran relaciones de fuerza y desigualdad?, ¿no sería necesario contar con un mecanismo que sometiera a crítica esas prácticas intersubjetivas que deben dar lugar a consensos no forzados? Desde la perspectiva crítico-práctica, esta carencia es efecto de la valoración pragmatista del conflicto y la competencia como elementos disgregadores de las formas de vida comunitaria ${ }^{35}$. De aquí que se insista en las capacidades benéficas de resolución y homogeneización de las prácticas comunicativas y consensuales en detrimento de una labor crítica de las mismas; en otras palabras: el pragmatismo tiende a no considerar el conflicto como elemento estructural de dichas prácticas, o al menos cree que no debe serlo. A partir de estas matizaciones podemos comenzar a esbozar la propuesta crítico-práctica.

Apoyándonos en la sociología de la ciencia de P. Bourdieu, cabe concebir la disciplina historiográfica como un campo social. La cuestión está en dirimir hasta qué punto este campo es susceptible de ser tratado bajo la teoría general de los campos y hasta qué punto adquiere propiedades específicas ${ }^{36}$. Como veremos, las propiedades específicas de las que se dota el campo historiográfico vienen proporcionadas por su ubicación en un campo de orden más general: el campo científico. Por lo demás, cabe aplicar la teoría de los campos y concebir la historiografía bajo una doble condición: como un campo de fuerzas y como un campo de luchas ${ }^{37}$.

La primera definición hace referencia a un constructo analítico que nos permite dar cuenta de la estructura objetiva de relaciones que se establece en un determinado momento entre los diferentes agentes (individuos o comunidades) implicados en el campo; es decir, una estructura de relaciones más allá de las interacciones concretas entre los agentes. Esta estructura responde a la correlación de fuerzas existente en virtud de la desigual distribución (cuantitativa y cuali-

35. Norriel, Gérard, Sobre la crisis..., p. 180.

36. BOURdieu, P., El oficio del cientifico..., p. 15.

37. Ibidem, pp. 64-69. Sobre el concepto de campo social, Bourdrev, Pierre, Questions de sociologie, Paris, 1984, pp. 112-113. 
tativa) de los recursos disponibles. El valor específico de estos recursos -conceptualizados por Bourdieu como capital-varía según el campo en el que nos ubiquemos. Así, por ejemplo, mientras que en el campo del mercado el recurso que adquiere más valor es el capital de tipo económico, en el de la historiografía (ubicada en el campo de las ciencias sociales) este papel preponderante es asumido por el capital científico ${ }^{38}$. Según Bourdieu, el capital científico no es sino un tipo de capital simbólico; es decir, un recurso producto de la percepción (actos de conocimiento y de reconocimiento) por parte de los agentes que pertenecen al campo. El capital científico funciona por tanto como una especie de "crédito" que necesita de la complicidad del resto de los implicados: el científico es conocido por una contribución distintiva que aumenta el capital colectivo de la disciplina; contribución que a su vez es reconocida mediante múltiples vías (publicaciones prestigiosas, citas, congresos, etc. $)^{39}$. Dado que estos recursos se encuentran desigualmente repartidos podemos realizar una distinción fundamental entre aquellos agentes que ocupan una posición dominante en la estructura del campo y los que ocupan una posición dominada. Por otro lado, disponer de gran cantidad de capital científico es lo que permite a los agentes que ocupan una posición dominante ejercer un poder sobre los criterios que regulan el reparto de nuevos recursos. En el campo de la historiografía, estos criterios responden a las normas que regulan la elaboración de relatos históricos y su validación; o lo que es lo mismo: a los principios que establecen una línea divisoria entre lo que se considera un producto historiográfico adecuado y lo que no.

Ahora bien, según la segunda definición, las disciplinas también se configuran como campos de lucha en los que tiene lugar pugnas entre los agentes, desigualmente equipados, con el fin de conservar o transformar la correlación de fuerzas del campo. Un campo científico se configura así, como un espacio de lucha entre agentes que pugnan por acumular el capital científico necesario para controlar los criterios que regulan el reparto de nuevos recursos. Aunque las estrategias concretas que adoptan los agentes en pos de dicho objetivo vienen determinadas por la posición específica que ocupan en la estructura del campo de fuerzas y por la representación que se hace de la que ocupan sus competidores; éstas siempre se van a organizar en torno a la oposición fundamental dominantes-dominados. Así, aquellos que ocupan una posición dominante, tienden a desarrollar estrategias de conservación de la estructura del campo que les es favorable, imponiendo como norma universal los principios implícitos en su práctica (objetos, métodos, criterios de validación, etc.). Los dominados,

38. Esto no significa que la posesión de otras especies de capital sea irrelevante a la hora de establecer la estructura de relaciones de fuerzas que conforman el campo, máxime cuando es posible transformar un tipo de capital en otro. En la línea de los ejemplos presentados piénsese en el papel creciente que desempeña el denominado capital intangible en el campo económico (Pérez, Julio, "España en la encrucijada del capitalismo global", Actas del IV Simposio de Historia Actual, 2004, p. 4-7) o el del capital temporal (v.g. administrativo) en el campo de las ciencias. Sobre los diferentes tipos de capital véase el capítulo 4 de Bourdieu, Pierre, Poder, Derecho y Clases sociales, Bilbao, 2000, pp. 131-165.

39. Bourdieu, Pierre, El oficio del cientifico..., p. 101. 
en cambio, desarrollan estrategias que aspiran a revolucionar la estructura del campo, introduciendo -y pretendiendo que sean reconocidas- nuevas «formas de hacer» críticas con los principios sobre los que se sostiene el reparto de beneficios que les es desfavorable $e^{40}$.

Llegados a este punto vemos como a través de la noción de campo, la propuesta crítico-práctica se dota de recursos que permiten poner de manifiesto las relaciones de fuerza y las luchas que estructuran las prácticas intersubjetivas de las que emana la normatividad vigente. El pragmatismo, al centrar su atención en las condiciones que permitirían resolver los conflictos y articular una comunidad historiográfica no contempla -o al menos no desarrolla - una concepción de la historiografía como universo competitivo en el que, diferentes comunidades equipadas con desiguales recursos pugnan por imponer y legitimar los principios implícitos en su práctica. De aquí que el pragmatismo carezca de un mecanismo crítico eficiente que ponga de manifiesto las relaciones de poder contenidas en los procesos deliberativos y las prácticas consensuales, así como los sesgos implícitos en los principios en los que deben basarse esos acuerdos.

Ahora bien, ante esta acusación, el pragmatismo lanzaría los siguientes desafíos: si la normatividad que regula la relación sujeto-objeto es el resultado de una pugna entre los diferentes agentes del campo ¿cómo es posible trascender el conflicto de intereses individuales y producir conocimientos con validez intersubjetiva?, ¿no se estaría resucitando así una suerte de "nihilismo textualista" por el que la historiografía queda reducida, no ya a una pugna retórica entre diferentes relatos, sino una "mezquina" lucha de poder entre los historiadores por imponer "su verdad"? ${ }^{41} Y$ en el mismo sentido, ¿cómo vamos a llevar a cabo esa labor crítica si no podemos trascender nuestro propio punto de vista e introducir, en consecuencia, un fundamento desde el que ejercer esa crítica?, ¿cómo podemos ser juez y parte? Comenzando por la segunda pregunta, la propuesta crítico-práctica entiende que es posible ser juez y parte siempre que el punto de vista crítico aplique sus propias armas sobre sí mismo: una crítica de la crítica (una objetivación del objetivador, una historización del historiador) que ponga de manifiesto los sesgos implícitos en la constitución de dicha mirada ${ }^{42}$.

Respecto a la primera pregunta, la respuesta es no. La propuesta crítico-práctica va a escapar a esta antinomia conflicto-norma recordando que la dimensión conflictiva de las prácticas intersubjetivas también se encuentra sometida a una serie de reglas ${ }^{43}$. Estas reglas -resultante histórica de la forma en la que se ha configurado el campo científico antes que propiedad trascendental de la ciencia- su-

40. La búsqueda de réditos científicos y la implicación en las luchas no supone -al menos no siempre- una actitud cínica por parte del historiador. Éste realmente puede estar motivado por un interés en el desinterés -y de hecho así debe parecer-, es decir, un interés en el avance colectivo de la disciplina, aunque su propuesta, una vez reconocida, pueda implicar la pérdida de recursos científicos por parte de sus competidores y el incremento de los suyos.

41. Notruel, Gérard, Sobre la crisis..., p. 166.

42. Desarrollaremos los efectos de esta propuesta -que en el caso de Bourdieu queda conceptualizada como autosocioanálisis- de forma más pormenorizada en el siguiente apartado.

43. Bourdieu, Pierre, El oficio del cientifico..., pp. 111 148. 
ponen tres constantes estructurales. En primer lugar, es posible la existencia de una normatividad con validez intersubjetiva en tanto que los diferentes agentes se han tenido que dotar de una serie de principios comunes para poder competir. Esta exigencia viene impuesta por el carácter de los recursos en juego. Dado que el capital científico es un tipo de capital simbólico necesita, para ser efectivo, del conocimiento y reconocimiento del resto de los integrantes del campo. Por tanto, éstos deben compartir, al menos, ciertos principios que les permitan desarrollar, reconocer y diferenciar aquellas prácticas adecuadas de las que no los son. ¿De qué forma se dotan los diferentes agentes de estos principios compartidos? En este punto cabe introducir la noción de habitus ${ }^{44}$. Hemos señalado más arriba que las estrategias y prácticas del agente están determinadas por la posición que ocupa en el campo y por la percepción de la que ocupan sus competidores. Ahora bien, esta determinación no se ejerce de manera mecánica, ni sobre una suerte de sujeto trascendente o natural, sino sobre unos agentes constituidos como habitus. El concepto de habitus -en nuestro caso el habitus del historiador- hace referencia al conjunto de disposiciones adquiridas (o convenciones implícitas de comportamiento) que habilitan al historiador para desenvolverse con aparente "naturalidad» en el campo historiográfico. Lejos de una noción de raigambre intelectualista o discursiva, el habitus se configura como un sentido práctico, un "sentido del juego" adquirido a través de un aprendizaje no explícito, de una experiencia acumulada o familiarización rutinaria, de las reglas, de la normatividad que regula el juego del campo ${ }^{45}$. De esta manera, incorporar dichas reglas supone, por un lado, convertirlas en recursos disponibles para su aplicación práctica; por otro, su aceptación implícita y el compromiso de someterse a ellas (v. g. criterios que regulan la elaboración de relatos, uso de determinadas técnicas, no invención de documentos, etc.). Una vez que han sido incorporadas, el agente adquiere la habilitación necesaria para desarrollar estrategias y prácticas acordes a la estructura del campo y reconocer como tales las de otros; en otras palabras: alcanza competencia (dominio del oficio) para llevar a cabo y reconocer un comportamiento historiográfico adecuado ante una situación concreta. En definitiva, esta adquisición de competencia a través del proceso experiencial de constitución del habitus -y por el que los diferentes agentes, independientemente de sus trayectorias particulares, se dotan de una serie de principios compartidos- se convierte en requisito inexcusable para ingresar en el campo (estableciendo por tanto una censura entre insiders y outsiders) y competir adecuadamente en él.

Si bien esta constante hace referencia a lo que podemos denominar como «la necesidad de tener algo en común de qué hablar para poder discutir», la segunda haría referencia a la «manera de hablar». Dadas las características del capital en juego, los campos científicos se han configurado de tal forma que las prácticas de los agentes y los criterios en ellas implícitos deben ser reconocidas por los

44. Sobre el concepto de habitus, Bourdieu, Pierre, Le Sens Patrique, Paris, 1980, pp. 92-93.

45. Es importante hacer notar en este punto que el habitus no supone una ejecución automática de la normatividad del campo. Toda vez que actúa como recurso movilizable ante situaciones concretas el habitus hace valer la creatividad de los agentes en el diseño de estrategias. 
competidores más directos y habilitados. Es precisamente esta necesidad de entrar en conflicto para adquirir capital científico, de someterse a las más certeras objeciones de quienes más interesados están en particularizar dichas prácticas y principios, lo que hace que, una vez superadas esas objeciones, adquieran validez intersubjetiva ${ }^{46}$. Es más, al someterse victoriosamente a dichas pruebas, el agente puede acumular el capital necesario para variar la correlación de fuerzas del campo y transformar, llegado el caso, toda la normatividad vigente.

De esta forma, y con esto entramos en la tercera constante, los campos científicos se han configurado de tal manera que la irrupción de una nueva normatividad no surge exnovo, sino a partir de una reconfiguración de la normatividad anterior. Efectivamente, como hemos señalado, el habitus es una disposición que permite convertir la normatividad vigente en recursos para el desarrollo de estrategias socio-cognitivas acordes a la estructura del campo. Pero a diferencia del mal jugador-cuyas estrategias siempre van a rebufo de los cambios en el estado del juego-el buen jugador es aquel cuyo habitus es capaz de adelantarse al futuro del campo y usar la normatividad vigente para desarrollar estrategias acordes a esa virtualidad. Convertida esa normatividad en un campo de posibilidades, puede combinar elementos que antes parecían inconexos, creando una novedad, provocando una ruptura y abriendo una nueva fase del juego. Por tanto, el dominio del oficio (de su normatividad) en forma de competencia, no sólo es necesario para entrar a formar parte del juego, sino que se constituye en requisito ineludible a la hora de innovar y producir una ruptura. Lo importante es que, dado que esta ruptura se entiende en términos de posibilidades y recombinación de elementos existentes, queda abierta una vía para que el resto de los integrantes del campo estén en disposición de reconocer, más tarde o temprano, la novedosa y distintiva contribución del innovador.

En conclusión, a partir de estas tres constantes la propuesta crítico-práctica resuelve la antinomia conflicto-norma al entender que es posible una normatividad que trascienda los intereses individuales de cada competidor. Ahora bien, ¿son los campos científicos entes aislados del universo social en el que se ubican?, ¿cómo afecta esta exterioridad a la interioridad del campo, al desarrollo de su lógica y normatividad? Según Bourdieu, la dinámica de un campo no sólo está sometida a la tensión interna que supone el configurarse como un campo de luchas, sino también a la presión externa efecto de la acción que ejercen otros campos sobre él ${ }^{47}$. Esta presión -que resulta una variable histórica cuya magnitud es inversamente proporcional al grado de competencia requerido para ingresar en el mismo- determina la estructura del campo de fuerzas (introduciendo nuevos recursos, trastocando las fronteras del campo, etc.) y en conse-

46. De aquí que los principios con validez intersubjetiva sean un acto de producción colectiva en el que está implicado todo el campo. Si bien la acción de los agentes -en sentido positivo, creativo- es necesaria, no lo es menos la de los competidores -en sentido negativo-; es decir, cuando intentan refutar un producto o una norma infructuosamente estarían contribuyendo a su reconocimiento.

47. Bourdiev, Pierre, El oficio del cientifico..., p. 87. 
cuencia las luchas que configuran la normatividad vigente. No obstante, esta determinación no se ejerce de forma mecánica. Para que la presión del universo social surta efecto sobre el campo «debe someterse a un ejercicio de transfiguración que la retraduce al lenguaje, a los debates, a las posiciones que estructuran el campo" ${ }^{48}$. De ahí que, en virtud de esta cualidad particular, se consideren las estructuras de los diferentes campos sociales, antes que idénticas, homólogas ${ }^{49}$. En definitiva, ni los campos son entes completamente autónomos, ni resultan un reflejo mecánico del universo social en el que se ubican: los campos guardan ciertas homologías entre sí a la vez que gozan de autonomia relativa para desarrollar su lógica interna.

Cabe concluir, por tanto, que para la propuesta crítico-práctica, la normatividad que regula la elaboración de relatos históricos y su validación, no es sino una construcción colectiva efecto combinado de las luchas históricas por imponer los criterios que regulan el reparto de capital científico (es decir, la normatividad considerada legítima) y las presiones a las que ha estado y está sometido el campo historiográfico. La naturaleza de la historiografía deja de considerarse representacionista, retórica, convencional o consensual y deviene efecto de una práctica colectiva de cooperación y conflicto.

\section{EL CAMPO HISTORIOGRÁFICO DE LA DÉCADA DE LOS 90}

Una vez que hemos presentado a los diferentes agentes y nos hemos dotado de los recursos necesarios, podemos pasar a reconstruir la historia reciente del campo historiográfico. En este sentido, la primera cuestión es determinar cómo la historia social llegó a constituirse y se mantuvo como paradigma dominante hasta finales de la década de los 80.

A lo largo del siglo XIX la historiografía había alcanzado el estatus de disciplina autónoma y reconocida en el mundo académico. El surgimiento de este nuevo campo científico se vería posibilitado por la convergencia de dos acontecimientos decisivos. Externamente, los procesos de constitución de los Estados-nación supondrían la intervención activa de unos poderes estatales que, a cambio de promover la institucionalización y autonomía de la nueva disciplina, exigirían legitimación por parte del funcionariado encargado de gestionarla. Internamente, este reconocimiento como ciencia autónoma se vería consolidado por toda una serie de prácticas específicas que ponían la primera piedra en la constitución del moderno oficio del historiador: técnicas de explotación y gestión de los recursos archivísticos, crítica de fuentes, reglas formales

48. VAzQuez, Francisco, Pierre Bourdieu. La sociología como crítica de la razón, Barcelona, Ediciones de Intervención Cultural, 2002 , p. 46.

49. V. g. el campo historiográfico está sometido a una presión mucho mayor por parte del campo político -y por tanto goza de menor autonomía- de la que lo está el campo matemático. Así, los conflictos políticos suelen refractarse, en gran medida, en los conflictos historiográficos. No obstante, las pugnas políticas deben traducirse al lenguaje historiográfico, de forma que, por ejemplo aun reproduciéndose la escisión derecha-izquierda, apelar a la filiación política en una disputa historiográfica no constituya un argumento reconocido. 
requeridas en la presentación pública de investigaciones, normativización y desarrollo de disciplinas auxiliares, etc. El prestigio social e intelectual del que gozaría la historiografía a lo largo del siglo XIX y primer tercio del siglo XX sería capitalizado por el paradigma de la historia tradicional. Pese a las diferentes variantes nacionales y culturales ( $v$. g. la escuela metódica francesa, la historicista alemana o la historiografía de Oxbridge), existen los suficientes elementos comunes compartidos para hablar de un paradigma homogéneo escasamente cuestionado. De esta manera, el paradigma de la historia tradicional ocuparía una posición dominante en el campo historiográfico, lo que le permitiría imponer como norma universal los principios implícitos en su práctica $(v \cdot g$. respecto a la noción y tratamiento del documento histórico).

Ahora bien, durante el primer tercio del siglo XX jóvenes historiadores que habían sido formados en el paradigma tradicional (M. Bloch, L. Fevbre, M. Dobb, etc.), comienzan a articular -cada uno desde un determinado ámbito del campo y equipado con un habitus particular (según la tradición nacional, influencia teórica, etc.)- una nueva propuesta que desembocaría en un cuestionamiento de la normatividad hasta entonces vigente. El nuevo paradigma de la historia social se iría abriendo paso a través de un complejo proceso en el que, nuevamente, coadyuvarían elementos externos e internos al campo historiográfico.

Así, respecto a la exterioridad del campo, la nueva propuesta iría capitalizándose en relación a la dinámica de otros campos sociales, científicos y no científicos. Las profundas transformaciones sociales ocurridas a comienzos del siglo XX junto con el cuestionamiento al que estaban siendo sometidos los Estados-nación que habían llevado a Europa a la Gran Guerra, provocaron, no sólo el desprestigio de un paradigma tradicional estigmatizado por su estrecho vínculo con el nacionalismo, sino la demanda social de una historiografía capaz de dar respuesta a los nuevos problemas de una "sociedad de masas". En este sentido, la irrupción de nuevas disciplinas en el campo de las ciencias sociales ( $v$. g. la demografía), se convertirían en nuevas bazas para el nuevo aspirante a paradigma dominante, toda vez que éstas no podían ser explotadas como ciencias auxiliares por la historia tradicional sin cuestionar los principios implícitos en su práctica.

En el interior del campo historiográfico, la nueva propuesta se capitalizaba merced a un proceso en el que confluían diversos fenómenos. En primer lugar, la prolongada vigencia del paradigma tradicional hacía concebir a estos jóvenes historiadores la necesidad de innovar para adquirir un perfil distintivo en el campo. De aquí que, pese a haber sido formados en dicho paradigma, se mostraran muy receptivos a las nuevas «formas de hacer» que se extendían por las diferentes ciencias sociales. Esta receptividad a nuevos recursos teóricos y técnicos, permitió abrir nuevos espacios antes vedados por la propia lógica del paradigma tradicional. Entre otros: una nueva concepción de la realidad social (entendida como un sistema de estructuras funcional o causalmente interrelacionado), un concepto más amplio del oficio de historiador (respecto a las fuentes, a las técnicas y disciplinas utilizadas) y finalmente, una clara apuesta por el 
representacionismo crítico (apuesta de los fundadores de la historia social que, sin embargo, no sería asimilada del todo por muchos «discípulos» quienes, aun produciendo conocimientos a partir de las dos contribuciones anteriores, no dejarían de considerar dichos conocimientos como una copia de la realidad social). Sea como fuere, el hecho es que estos historiadores podían ya presentarse como los protagonistas de una contribución que aumentaba los recursos colectivos de la disciplina. Esta estrategia se vio acompañada por una consciente necesidad de controlar determinadas instituciones académicas y editoriales con el fin de hacer pública la nueva propuesta; maniobra favorecida por el inevitable relevo generacional en muchas de estas instancias. A través de este complejo proceso, el nuevo paradigma de la historia social que comenzaba su periplo desde una posición subordinada en el campo historiográfico comenzaría a acumular el capital científico suficiente como para trastocar la correlación de fuerzas del campo, pasar a ocupar una posición dominante y estar en disposición de universalizar, lenta pero progresivamente, los principios implícitos en su práctica.

Este proceso se vería consolidado a partir de los años 50 por un reconocimiento social merced al vínculo de muchas de sus cabezas visibles a la causa antifascista (M. Bloch, fusilado por su implicación en la resistencia francesa, F. Braudel, que esboza las líneas maestras de lo que será El Mediterráneo en un campo de concentración, la joven generación de lo que será el núcleo de los historiadores sociales británicos: militantes del partido comunista inglés y combatientes en la II Guerra Mundial, etc.). De esta forma, el paradigma de la historia social (ya fuera en su variante Annales ya en la del materialismo histórico) conocería una carrera ascendente que le llevaría a ser reconocido -dentro y fuera del campo historiográfico, con más o menos ajustes- como la forma adecuada de hacer historia durante al menos 30 años.

Ahora bien, esta posición prácticamente indiscutida comenzaría a quebrarse desde dos frentes: la historia sociocultural, que comienza a fraguarse desde la década de los 70, y la irrupción posterior en el campo historiográfico, ya en los años 80, del GL. La aparición de ambas propuestas deben, en primer lugar, ponerse en relación con fenómenos extemos al campo. En este sentido, el carácter de los movimientos sociales acaecidos a ambos lados del muro de Berlín a finales de la década de los 60 habrían introducido en el orden del día de las ciencias sociales la necesidad de revisar la teoría social de corte objetivista con la que los paradigmas dominantes de las diferentes disciplinas encaraban el análisis de los fenómenos de acción individual y colectiva. Se constataba así las carencias de un modelo teórico que al reducir la esfera de la subjetividad a un epifenómeno de la estructura social objetiva quedaba desprovisto de los recursos necesarios para comprender la complejidad de los procesos sociales.

En el campo historiográfico comenzarían a circular desde la década de los 70 , voces críticas que pretendían matizar y superar el utillaje conceptual de la teoría social de la ortodoxia marxista y del estructural-funcionalismo de Annales. Estos historiadores, formados en primera instancia en el paradigma de la historia social, toman distancia respecto a su formación original al sostener que la determinación de las estructuras objetivas sobre la identidad y la acción 
subjetiva sólo se ejerce a través de los dispositivos culturales y cognitivos con los que el agente se encuentra equipado. Esta reorientación de signo culturalista explica el interés de estos historiadores por aproximarse a una antropología, por entonces de reconocido prestigio, en detrimento de aquellas disciplinas que habían sido cultivadas intensivamente por la historia social ( $v . g$. demografía, economía). Hacía así su entrada en la escena del campo historiográfico la historia sociocultural -ya en su variante de los III Annales en Francia, ya en la versión culturalista del marxismo anglosajón, ya en la de la microhistoria italiana, etc.- apostando por una reorientación de la investigación histórica hacia el estudio de los dispositivos culturales, simbólicos y de mentalidad. La combinación de esta dinámica externa e interna al campo historiográfico permitiría que estos historiadores se capitalizaran frente a los que aún practicaban la historia social convencional: todas las grandes figuras de la historiografía de los años 70 y 80 cultivarían un tipo u otro de historia sociocultural ( $v . g$. E. P. Thompson, E. Hobsbawm, G. Duby, J. Le Goff o C. Ginzburg, entre otros).

No obstante debemos ser cautos a la hora de valorar esta vocación rupturista de la historia sociocultural. Ciertamente, al insistir en la necesidad de pensar la esfera de la subjetividad desde nuevos parámetros, el nuevo paradigma introduce importantes matices respecto a la teoría de la sociedad con la que trabajaba la historia social. Por otro lado, ese interés por los dispositivos culturales y cognitivos de las subjetividades también introdujo ciertos matices respecto a la epistemología de la historia social: por un lado, todos los historiadores socioculturales se ubican definitivamente en el representacionismo crítico; por otro, esta apuesta adquiere un perfil propio, al entender los recursos teóricos que intervienen en el proceso de investigación bajo una concepción más dinámica (de una estructura conceptual fija, a una guía o marco interpretativo que orienta el proceso $)^{50}$. Ahora bien, a pesar de estas diferencias -o precisamente por ellas- la historia sociocultural no implica una ruptura definitiva con el paradigma de la historia social. Se trataría más bien de una prolongación crítica que hace bascular el modelo dicotómico hacia la esfera del sujeto, con el fin de establecer un equilibrio o mediación entre ambas instancias ignorado por el «imperio del objeto». Sin duda ésta es una de las razones que explica por qué no somos testigos de un profundo enfrentamiento entre historiadores socioculturales e historiadores sociales, sino, antes bien, de una suerte de «reforma pactada» (v. g. el paso de la II a la III generación de Annales) o "convivencia tolerada». A excepción de algunos conatos especialmente virulentos ( $v . g$. la agria disputa en el seno del marxismo anglosajón de finales de los años 70 entre economicistas y culturalistas), lo que observamos es una progresiva capitalización de la historia sociocultural que no conlleva una excesiva pérdida de capital científico entre aquellos que habían cultivado o seguían cultivando una historia social de reconocido prestigio ${ }^{51}$.

50. Cabrera, Miguel Á., "La situación actual de la historia...., p. 15.

51. De hecho no pocos historiógrafos considerarian que la historia social y sociocultural conformarían un mismo paradigma. No obstante, como señalábamos en la introducción, hemos creído conveniente distinguirlos, no sólo para remarcar su particularidad, sino porque, como veremos 
Ahora bien, la nueva problemática que los movimientos sociales de finales de los 60 habían introducido en el campo de las ciencias sociales no sólo desembocó en la crítica sociocultural sino que, por un camino bien diferente, contribuiría de manera decisiva a producir, ya en la década de los 80 , la primera ruptura con la epistemología representacionista. Jóvenes historiadores herederos de la tradición del estructuralismo francés de los años 60 (v.g. de la semiótica de Barthes, de la antropología de Lévi-Strauss o del marxismo de Althusser) y formados en la producción intelectual posestructuralista desarrollada con posterioridad a los sucesos de mayo del 68, acaban por introducir en el campo historiográfico «el problema del lenguaje» en los términos estipulados por el GL. Al sacar a la palestra la condición narrativa de la historiografía, al conocer una rápida difusión en diferentes espacios editoriales y tradiciones nacionales y al experimentar un notable éxito entre los historiadores más jóvenes, la nueva historiografía inspirada en el GL se revelaría definitivamente como el primer desafío radical a la epistemología representacionista en la que se inspiraban los paradigmas hasta entonces dominante.

Por tanto, en los años 80 el panorama historiográfico responde a un complejo equilibrio por el que la historia social va cediendo lentamente posiciones frente a la historia sociocultural, mientras, diferentes historiografias inspiradas en el GL presentan un radical desafío a los fundamentos teóricos de ambas propuestas. En ese contexto, tres fenómenos van a precipitar los acontecimientos.

En primer lugar, la década de los 80 conoce los efectos de la recesión en la contratación del mercado laboral universitario que habría tenido lugar en la década de los $70^{52}$. Resultado de una «superpoblación académica» acaecida durante los años 60 esta situación va a provocar un envejecimiento generalizado del cuerpo docente y el descontento de muchos jóvenes historiadores que ven frustradas sus expectativas de encontrar un empleo en la universidad. Tanto en Estados Unidos, en Francia, en Gran Bretaña o en Alemania, muchos de estos jóvenes historiadores "expulsados de la comunidad" se verían obligados a ofrecer sus competencias a otras instituciones, fuera de la "fortaleza universitaria". De esta forma, y no olvidado el agravio, los conflictos entre instituciones y la denuncia de la historia oficial (que también hallaba eco en el interior de la propia academia) se van haciendo cada vez más ostensibles a medida que avanza la década de los 80; lo que se va a traducir en la multiplicación de las polémicas referidas a las pretensiones de objetividad del saber histórico y a la complicidad que éste mantiene con los poderes establecidos.

En este contexto profesional y generacional acaece la caída del Muro de Berlín, lo que supone el derrumbe del proyecto social que -con mayor o menor adscripción- legitimaba la historiografía de inspiración marxista. La victoria del capitalismo y de la democracia liberal sobre el bloque del Este se refractó

posteriormente, los historiadores socioculturales pretendían tealmente presentarse como una alternativa a la vieja historia social.

52. NoIRIEL, Gérard, Sobre la crisis..., p. 27. 
rápidamente en el campo de las ciencias sociales en una fulgurante pérdida de crédito de las propuestas teóricas basadas en la tradición del materialismo histórico. Por lo que respecta al campo historiográfico, no sólo el materialismo histórico objetivista de la historia social se vería profundamente cuestionado por este nuevo contexto social y político, sino también el materialismo histórico "culturalista" vinculado a la historia sociocultural.

Finalmente, el tercer proceso implica a la escuela de Annales que, si bien hubo de encarar un desafío de carácter bien distinto al que tuvo que enfrentarse el marxismo, se vio abocada a un desenlace de consecuencias similares. Efectivamente, las generaciones de historiadores que conviven en el período de los III Annales (ya practicando historia social, ya historia sociocultural), van a sufrir a lo largo de los 80 un proceso creciente de especialización temática, metodológica y finalmente teórica que culmina con una definitiva fragmentación de la escuela y una pérdida de la identidad colectiva, en lo que F. Dosse acertó a denominar como "la historia en migajas".

En conclusión, en un conflictivo escenario laboral e intergeneracional como trasfondo, las dos escuelas más fecundas de la historia social y sociocultural perdían ese reconocimiento casi unánime del que habían gozado durante tres cuartas partes del siglo. ¿En qué posición quedaban los diferentes agentes del campo historiográfico como resultado de esta nueva situación?, ¿qué estrategias desarrollaron para inclinar la balanza de la nueva correlación de fuerzas en su beneficio?

Ante la arremetida conjunta de la pérdida del referente marxista, de la fragmentación de Annales y de la ofensiva teórica del GL, la mayoría de los agentes ubicados en la órbita de la historia social (fueran representacionistas ingenuos o críticos) asumen y alimentan el discurso de la "crisis de la historia». Con esta estrategia -compartida por no pocos historiadores socioculturales- los historiadores sociales pretenden universalizar la crisis de su paradigma haciéndola extensible a toda la disciplina, con el fin de implicar a todo el campo historiográfico y amortiguar así los efectos de la ofensiva de la que eran blanco: la apelación a la "crisis de la historia" se trataba, por tanto, de un recurso defensivo con el que frenar la inexorable pérdida de capital científico que estaban sufriendo. A partir de aquí pueden distinguirse, no obstante, tres grupos de historiadores sociales con estrategias concretas, según el carácter del habitus en cuestión.

Un primer grupo sería aquel que lo componen, bien historiadores que pertenecen a generaciones mayores y que cuentan con toda una vida dedicada a la práctica de la historia social, bien historiadores que siempre se habrían mostrado reacios a la innovación teórica y que sostendrían su prestigio, exclusivamente, en el hecho de aplicar acríticamente los protocolos de la historiografía dominante. En líneas generales, la estrategia de ambos consiste en ignorar lo ocurrido y aferrarse al capital acumulado durante la etapa anterior, lo cual, sin duda, se presenta en principio como la opción más viable aunque, como contrapartida, va a suponer un desfondamiento constante de sus recursos científicos.

En cambio, entre aquellos historiadores sociales más jóvenes, más innovadores o simplemente más dispuestos a encarar el desafío, podemos distinguir 
dos estrategias diferenciadas. En primer lugar una opción que combina un furibundo ataque al GL con un ejercicio de revisión que pretende culminar en una renovación de la historia social que no suponga el abandono del modelo representacionista. En ocasiones, esta maniobra permite mantener cierto volumen de capital, no sólo porque estos historiadores se encuentran mejor dispuestos y preparados que los anteriores para abordar debates de índole teórica, sino porque, precisamente a causa de dicha disposición, será la «estrategia de conservación" menos desacreditada por sus competidores ${ }^{53}$. La segunda estrategia que podemos distinguir dentro de este grupo consiste en abandonar definitivamente el paradigma de la historia social y apostar por la integración en algunos de los nuevos candidatos que junto con los inspirados en el GL van a irrumpir en la escena historiográfica. El desenlace de este proceder resulta divergente: frente a una minoría que, bien pertrechada teóricamente -y normalmente ya ubicada en el seno del representacionismo crítico- pretende intervenir y mediar en el perfil de las nuevas propuestas; se sitúa una mayoría cuya acción se limita a realizar apresurados actos de constricción con el fin de enmendar los vínculos con una tradición ahora en descrédito. Mientras los primeros consiguen «trasladar y vincular" su capital científico a las nuevas alternativas -de forma que su volumen de capital queda relativamente intacto- los segundos han seguido una trayectoria errática acompañada de una asimilación defectuosa de los principios implícitos en los nuevos candidatos a paradigma, lo que se habría traducido en una progresiva pérdida de crédito científico.

Finalmente, podemos distinguir un tercer grupo de historiadores sociales cuya trayectoria bien merece tratarse por separado. En este caso la estrategia consiste en abandonar la historia social para reivindicar una vuelta a la vieja historia tradicional en connivencia, en este caso, con aquellos que no habían dejado de practicarla y que percibían que la nueva situación les abría un campo de posibilidades. No obstante, los efectos son contradictorios: apoyados en la posición favorable que les otorga la homología del campo historiográfico con la "revolución conservadora" acaecida en el universo social y contando con un masivo apoyo de los media, los "nuevos y viejos" historiadores tradicionales van a ver crecer su capital simbólico fuera del campo -y generalmente también el económico- de manera inversamente proporcional a como lo hace su capital científico en el interior del mismo ${ }^{54}$.

Ante el cariz que adquiere la debacle de la historia social y en la pugna que se desata a comienzos de los años 90 por establecer una nueva correlación de fuerzas, los agentes ubicados en la órbita del GL parecían ser los que contaban con las bazas más favorables. Varias razones pueden esgrimirse al respecto: primero, la profunda conmoción que sufre la disciplina sitúa el debate en una

53. Un ejemplo paradigmático en el universo hispano quizá sea FonTANA, Josep, La historia después del fin de la historia, Barcelona, 1994.

54. No obstante, esta pérdida de capital científico dentro del campo debe matizarse por lo que respecta a algunas de las grandes figuras de la historia social que optaron por dicha estrategia rupturista de corte conservador. 
esfera de orden teórico, lo que juega a favor del habitus de unos historiadores formados en estrecho contacto con la filosofía (en concreto con la filosofía del lenguaje); segundo: la irrupción generalizada del "problema del lenguaje» en todas las disciplinas sociales, elemento externo de presión sobre el campo historiográfico que representa una baza para estos historiadores; tercero: el haber sido los primeros en decretar -ya en la década de los 80- la defunción del representacionismo epistémico. Estos tres ingredientes van a permitir a los historiadores del lenguaje acumular el suficiente capital para imponer a todo el campo historiográfico como orden del día, la necesidad de reflexionar sobre la condición narrativa de la historiografía. A partir de esta posición de fuerza que les permite desplazar el debate teórico de la disciplina al terreno más favorable para su habitus, este grupo de historiadores ofrece la primera solución al vacío normativo que ha dejado la crisis del representacionismo que ellos mismos han contribuido a provocar: una solución de orden retórico, de nuevo, acorde a sus intereses en el campo. No obstante, dentro de este grupo podemos distinguir varias estrategias, de las que vamos a destacar dos.

Por un lado existen historiadores que, en su formación, no habrían dejado de tener contactos con la historia social y, fundamentalmente, con la historia sociocultural ${ }^{55}$. Estos vínculos con los viejos paradigmas no sólo serían de orden teórico sino también de carácter institucional, dada la presencia de muchos de estos historiadores en universidades, centros de trabajo o editoriales que se habían constituido como verdaderos buques insignia de la historia social y sociocultural ${ }^{56}$. Este grupo constituye el núcleo de la alternativa de la «new social history", cuya filiación a los postulados del GL viene acompañada de la reivindicación, en tanto que herederos, de una fructífera tradición empírica y teórica que, no obstante, debía ser superada.

Por otro lado, un grupo de historiadores que, aunque también inspirados en el GL, seguirían una trayectoria bien diferente. Con una vocación aún más rupturista que la de los «nuevos historiadores»-fruto de la combinación de la ausencia de esos «vínculos prestigiosos» que aquéllos podían capitalizar y de una formación más próxima a la crítica literaria que a la historiografía- constituyen la opción textualista. De gran aceptación en Francia, pero sobre todo en los Estados Unidos, el textualismo apela a la inexistencia de una barrera epistémica entre el relato histórico y el de ficción como la estrategia más adecuada para acumular capital científico, en tanto que supone desplazar la naturaleza del

55. Véase, por ejemplo, los casos de J. Scott o W. H. Sewell Jr. cuyos vínculos con el GL no pueden entenderse sin considerar la influencia ejercida en sus obras por la historia sociocultural británica (fundamentalmente en lo referente a la figura de E. P. Thompson). Respecto a la crítica a la que someten la historia sociocultural thompsoniana, Scorr, Joan, Gender and the Politics of History, New York, 1988, pp. 3-4 y Seweu, William H., "Critical Reflections on E. P. Thompson's Theory of Working-class formation", en KaYe, J. y MCLeldaNd, K. (eds), E. P. Thompson. Critical Perspectives, London, 1990 , pp. 50-77.

56. Es, por ejemplo, el caso de P. Joyce, uno de las figuras preeminentes de la Universidad de Manchester, institución convertida en símbolo internacional de la historia social británica. 
conocimiento histórico a un terreno adecuado a un habitus formado en la crítica literaria y la lingüística.

Ahora bien, este nuevo panorama no pintaba tan halagüeño para un gran número de historiadores formados en la historia sociocultural. Éstos, aun sin romper con el representacionismo, se consideraban como la alternativa crítica que lenta, pero progresivamente, estaba llamada a ocupar el lugar de la historia social. Sin embargo, la situación a la que se enfrenta el campo historiográfico a finales de la década de los 80 y principio de los 90 supone un salto hacia delante de tal calado que, finaimente, termina sobrepasando sus expectativas en cuatro frentes sucesivos. Primero: la puntilla final de la historia social irrumpe ipso facto, no desde sus filas, ni siguiendo una «transición pacífica», sino desde una nueva propuesta de vocación "rupturista». Segundo: la crisis no afecta exclusivamente a la historia social, sino que supone un definitivo cuestionamiento de la epistemología representacionista desde la que ellos mismos trabajaban. Tercero: la crisis del materialismo histórico y de Annales, a los que sin duda estaban vinculados, no deja de vivirse como una pérdida de referente. Finalmente: formados en un profundo antiestructuralismo y en la teoría de aquellas ciencias sociales que, a diferencia de la filosofía del lenguaje o la lingüística, gozaban de una mayor aplicabilidad empírica, ven en cambio como el debate se desplaza hacia dichas esferas. No es extraño que este grupo de historiadores percibiera la nueva situación como un verdadero desafío que hacía peligrar las posibilidades de rentabilizar el capital científico en juego y su posición en el campo. De aquí que -con la excepción de aquellos que, como en el caso de la historia social, se mantuvieron fieles a la forma de hacer historia con la que venían trabajando- la mayoría de estos historiadores comenzaran a diseñar nuevas estrategias a lo largo de los años 90 con el fin, no sólo de preservar el capital científico acumulado, sino de influir en la estipulación de los criterios de designación de los nuevos recursos. En este sentido, podemos distinguir el desarrollo de dos estrategias a las que, por otro lado, se sumarán de forma más o menos apresurada algunos historiadores sociales.

La primera de estas estrategias responde a un doble movimiento que, en función de la situación del campo, el tipo de formación y los objetivos propuestos se revelaba, en principio, como la más adecuada. En primer lugar -y a diferencia de la opción mayoritaria entre los historiadores sociales-esta estrategia pasa por asumir el "nuevo orden" impuesto por la irrupción del GL y la debacle de los paradigmas hasta entonces dominantes; es decir: la necesidad de llevar a cabo el definitivo abandono de la epistemología representacionista y asumir la condición narrativa de la práctica historiográfica. En segundo lugar, este movimiento debe ir acompañado de un paralelo alejamiento de los paradigmas inspirados en el GL. Esta exigencia supone la única forma de abandonar el representacionismo sin que implique la disolución como grupo en una propuesta en la que, por otro lado y dada su formación, no actuarían como punta de lanza. En definitiva, se trata de articular una crítica propia al representacionismo alternativa a la que ofrece el GL. La viabilidad de esta estrategia pasa por tanto, en primera instancia, por encontrar una fuente de inspiración teórica que permita 
conjugar ambos imperativos. Esta fuente de inspiración debe además ser acorde -en tanto que revalorice- a una formación mucho más familiarizada con los avatares de la investigación histórica que con los de la reflexión filosófica o la crítica literaria. En este sentido, la propuesta del GP se revela como sumamente atractiva: por un lado, puesto que su crítica al modelo representacionista se articula dando prioridad a la esfera de la práctica sobre la del discurso; por otro, porque ha sido aplicada con notable éxito en diferentes ámbitos de las ciencias sociales $(v . g \text {. antropología, sociología o ciencia política })^{57}$.

La trayectoria de estos historiadores y las exigencias de la situación a la que se enfrentan eclosionan en una determinada lectura de los recursos del GP que, aplicada sobre el problema de la naturaleza del conocimiento histórico, dará lugar al candidato a paradigma denominado como narrativismo crítico. Como hemos visto más arriba, esta propuesta se va a caracterizar por asumir la condición narrativa de la historiografía, si bien poniendo sobre la mesa las presiones cognitivas a la que está sometida la construcción de los relatos históricos. Estas presiones, aseguran, responden a las convenciones epistémicas que definen el oficio heredado; oficio que es aprendido y conocido por el historiador a través de su formación práctica. La estrategia responde por tanto a un intento de presentarse ante el campo historiográfico como la única propuesta que, alejada definitivamente del representacionismo, pone a salvo a la disciplina de los excesos a los que aboca el GL, ofreciendo una respuesta de orden convencionalista capaz de aunar las dimensiones narrativa y epistémica de la historiografía.

En la pugna con los candidatos inspirados en el GI por el capital científico en juego, el narrativismo crítico juega, por tanto, con dos bazas. En primer lugar, al sustentar dicha estrategia sobre la base del oficio heredado pone las bases para un amplio reconocimiento en detrimento de un GL que suele ser percibido por el grueso de los historiadores como excesivamente intelectualista. En segundo lugar, "la estrategia del oficio", invita a percibir la propuesta como un ejercicio de revalorización del capital que los historiadores tienen asociado a la producción de carácter empírico, lo que sin duda redunda en un potencial reconocimiento de la misma.

Ahora bien, a mediados de los 90 , un nuevo agente entra en escena. Reconociendo el estado de "crisis de la historia" -pero sin vincular a dicha estrategia su capital científico- los historiadores situados en la órbita del pragmatismo, apostarán por una reconstrucción de la disciplina a partir de ciertos recursos del GP como forma de mantener-y llegado el caso mejorar-su posición en el campo. Esta "estrategia de reconstrucción" responde en primer lugar a la percepción que estos historiadores tienen de la del resto de los agentes implicados en el juego. En este sentido, el representacionismo deja de considerarse una opción, a la vez que toda una gama de nihilismos posmodernos son percibidos como la amenaza más directa, quizá no tanto en sí mismos como por la fragmentación de la que se les acusa, aspiran a introducir en la disciplina. Hasta aquí la lectura

57. SCHATZKI, T. R. et al., The practice tum..., p. 1. 
que realizan estos historiadores coincide en gran medida con la que acertaban a vislumbrar aquellos que engrosaban las filas del narrativismo crítico. De hecho, la solución convencionalista va a ser asumida como punto de partida de la estrategia de reconstrucción. Ahora bien, se considera que ante la convulsa situación que vive la historiografía, el carácter cognitivo que el narrativismo crítico imprime a dicha solución no resulta lo suficientemente sólido como para dejar de hacer peligrar el capital científico que está en juego. En este sentido, y familiarizados con una lectura del GP inspirada en el neopragmatismo de J. Dewey y R. Rorty y en la historia de la ciencia de T. S Kuhn, este grupo de historiadores se encuentra en disposición de ofrecer una alternativa al narrativismo crítico, al desplazar la fuerza de los convencionalismos intersubjetivos hacia el terreno de la razón práctica.

A partir de este "habitus pragmático» se sostiene que la difícil situación por la que atraviesa la disciplina tendría como causa fundamental la pérdida de un lenguaje común, como consecuencia de la intromisión de problemáticas ajenas al oficio del historiador en sus disputas, fundamentalmente provenientes del campo de la filosofía. Esta pérdida del lenguaje común imposibilita explicitar criterios, definir problemáticas y contrastar conocimientos: la cohesión de la comunidad se pierde y la autonomía de la disciplina se resiente. Frente a esta situación, el pragmatismo apunta la necesidad de recuperar un lenguaje compartido sobre la base del patrimonio común del oficio, de forma que puedan articularse espacios de deliberación y consenso; deliberaciones y consensos lo más amplios posibles, guiados no por fundamentos onto-epistémicos, sino éticos: la solidaridad y justicia implícitas en una verdadera práctica democrática.

A nuestro juicio, al diseñar esta estrategia de reconstrucción desde el terreno de la razón pragmática $-\mathrm{y}$ confrontando dicha estrategia con la situación externa e interna del campo historiográfico-el pragmatismo goza de grandes expectativas a la hora de aspirar a paradigma dominante. En el interior del campo, tres serían las bazas con las que cuenta a la hora de rentabilizar dividendos simbólicos. En primer lugar, al apelar al oficio del historiador y al lenguaje que éstos comparten a la hora de resolver problemas concretos que les atañen, puede aspirar a compartir (o disputar) la principal fuente de recursos científicos del narrativismo crítico. Pero es más, puede llegar a constituirse como una propuesta aún más atractiva, al poner al descubierto la debilidad del narrativismo crítico a la hora de encarar un proyecto de reconstrucción disciplinar: reducir las convenciones a meras operaciones cognitivas, olvidando que éstas se producen como resultado de actos comunicativos y consensuales cuya fuerza se apoya, en última instancia, sobre principios éticos. De aquí, y en tercer lugar, que al introducir una disyuntiva entre fragmentación -efecto combinado del agotamiento del representacionismo y de los excesos posmodernos- y reconstrucción, el pragmatismo invita a ser percibido -dado un narrativismo crítico excesivamente débil- no como un paradigma más en el ya de por sí conflictivo panorama historiográfico, sino como una propuesta que permite a los historiadores hablar de su oficio y fomentar el desarrollo de prácticas democráticas en las formas 
de vida de la comunidad ${ }^{58}$; en otras palabras, como la única alternativa capaz de devolver a la disciplina cohesión, independencia y prestigio. Esta invitación a participar en el proyecto pragmatista puede ser fácilmente percibida por un gran número de historiadores como una implicación en el proyecto colectivo de "reconstrucción» de la disciplina, lo cual, sin duda, redundaría en un eventual incremento del volumen de capital científico de los pragmatistas.

Externamente, la baza fundamental del pragmatismo se sitúa en la homología de su visión del campo historiográfico con el universo social que le rodea. A nivel general, los problemas asociados a la práctica de la democracia y la fragmentación potencial o realmente conflictiva que sufren las diferentes sociedades a escala mundial, constituyen un terreno abonado para todo tipo de propuestas que defienden la necesidad de reestablecer -a través de un diálogo en el que estén presentes, de una u otra forma, los implicados- un consenso social lo más amplio posible en torno a las cuestiones claves que afectan a la convivencia democrática. En la misma línea, y por lo que respecta al universo intelectual en el que se ubica el campo historiográfico, cabe destacar, entre otras bazas favorables, el uso creciente en ciencias sociales y naturales de un lenguaje y unos esquemas interpretativos de la realidad elaborados en términos de comunicación e información, lo cual no deja de resultar un halagüeño panorama para una propuesta que concibe el consenso normativo como el resultado de prácticas comunicativas.

Ahora bien, esta reconstrucción de la historia reciente del campo historiográfico no sería completa si no contempláramos la propuesta que, en tanto que herramienta, nos ha permitido llevar a cabo dicho análisis. Pero este ejercicio de objetivación del objetivador -que en nuestro caso adopta la forma de un autosocioanálisis ${ }^{59}$ - no sólo es necesario para conjurar una parcial reconstrucción del campo, sino para reconocer los sesgos implícitos en el punto de vista que adoptamos, toda vez que éste no deja de ocupar una posición en el campo y es producto de un determinado habitus. En este sentido, la propuesta críticopráctica que hemos esbozado ocuparía una posición no dominante en el campo historiográfico y vendría caracterizada por un habitus en el que cabe destacar la presencia de tres elementos claves: las aportaciones de la filosofía de la práctica (GP) -fundamentalmente en la estela wittgensteiniana-, una analítica del presente de sesgo crítico y una decidida vocación a practicar una ciencia social empírica e interdisciplinar.

Fruto de esa posición no dominante y de un habitus conformado en las tradiciones señaladas resulta una estrategia de marcado carácter crítico y emancipador. Dicha estrategia suscribe dos objetivos fundamentales: en primer lugar, se pretende que el campo historiográfico adquiera una mayor autonomía frente a poderes espurios; en segundo lugar, universalizar el acceso al reparto de los recursos del campo. En pos de ambos objetivos, se pone en marcha una labor de

58. NoIRIEL, Gérard, Sobre la crisis..., p. 170.

59. Bourdieu, Pierre, El oficio del cientifico..., p. 164. 
problematización de todas aquellas prácticas naturalizadas que ocultan y perpetúan las relaciones de dominación existentes, ya dentro del campo, ya entre éste y otros campos. Como hemos visto, esta labor, apoyada sobre una concepción colectiva de la naturaleza del conocimiento histórico -en tanto que práctica de cooperación conflictiva-, se materializa al sacar a la luz las relaciones de fuerza y las luchas históricas a partir de las cuales emerge la normatividad vigente y el grado de autonomía del campo. A partir de aquí, es posible conocer las condiciones sociales reales necesarias para crear una dinámica de universalización del acceso al reparto de los recursos y aumentar la autonomía del campo, garantías ambas de una mayor cientificidad de la historiografía. No obstante esta estrategia resultaría inocua o fraudulenta siempre que el historiador en cuestión no asuma el compromiso de poner en manos de otros historiadores las herramientas pertinentes para que esa labor crítica se ejerza sobre su propia práctica: sólo así, se desocultan los sesgos implícitos en la misma y puede aspirarse a ese mayor grado de autonomía.

A partir de esta estrategia y teniendo en cuenta la posición no dominante que la propuesta crítico-práctica ocupa en el campo, es posible valorar las bazas con las que juega. A nuestro juicio, una de las bazas más importantes es su capacidad para ser percibida actualmente como espacio de confluencia por parte de una amplia gama de historiadores alineados en la tradición de una historiografía crítica: desde los herederos de un materialismo histórico que, alejados del representacionismo, están en disposición de aproximarse al ámbito del GP (historia ecológica, de la interacción social, del conflicto de clases, etc.) ${ }^{60}$ a una historiografía de corte foucaultiano que, alejada en este caso del textualismo, también se aproxima al GP (estudios de gubernamentalidad, culturales, de la diferencia, etc. $)^{61}$. Este espacio de confluencia en el que puede aglutinarse una buena parte de la tradición crítica historiográfica gozaría de reconocimiento teórico y empírico como para adquirir los réditos simbólicos necesarios para, al menos, consolidarse en el campo historiográfico. Y no sólo en este sentido. Si bien la propuesta crítico-práctica difícilmente llegue a constituirse en el próximo paradigma dominante, la suerte de gran parte de su capital está vinculada a su capacidad para ofrecer a la disciplina eficientes herramientas con las que llevar a cabo una "práctica de sí", confrontarse consigo misma y someterse a una crítica colectiva en torno a los procesos de producción de su normatividad; desafíos todos ellos que debe encarar una disciplina que, al menos, aspire a ganar en autonomía y cientificidad.

60. Véase el monográfico de History and Theory de diciembre de 2003, titulado "Environment and History" y en el que participan diferentes figuras ubicadas en el GP. Sobre los posibles vínculos de la historiografía thompsoniana con la propuesta de Bourdieu y el GP, véase GARCíA, Francis$\mathrm{co}$, "Para una ontología política de la fluidez social: el desbordamiento de los constructivismos", Politica y Sociedad, vol. 40, n. ${ }^{\circ} 1$ (2003), pp. 52-53; sobre Thompson como antecedente y Bourdieu como figura del GP, NOGALES, Antonio, "Reflexiones en torno al nuevo enfoque práctico", Gaceta de Antropología, n. ${ }^{\circ} 10$, texto 10-03, (1993).

61. Sobre la recepción de Foucault entre los historiadores véase VÁzouEz, Francisco, "Foucault y la Historia...", pp. 145-159. 